\title{
Consistency of ARESE II cloud absorption estimates and sampling
}

\author{
issues
}

L. Oreopoulos ${ }^{1.2}$, A. Marshak ${ }^{1.2}$, R. F. Cahalan ${ }^{2}$

1. Joint Center for Earth Systems Technology, UMBC, Baltimore, Maryland

2. Climate and Radiation Branch, NASA Goddard Space Flight Center, Greenbelt,

Maryland

submitted to JGR (Atmospheres)

February 5,2002 


\begin{abstract}
Data from three cloudy days (March 3, 21, 29, 2000) of the ARM Enhanced Shortwave Experiment II (ARESE II) were analyzed. Grand averages of broadband absorptance among three sets of instruments were compared. Fractional solar absorptances were $\sim 0.21-0.22$ with the exception of March 3 when two sets of instruments gave values smaller by $\sim 0.03-0.04$. The robustness of these values was investigated by looking into possible sampling problems with the aid of $500 \mathrm{~nm}$ spectral fluxes. Grand averages of $500 \mathrm{~nm}$ apparent absorptance cover a wide range of values for these three days, namely from a large positive $(\sim 0.011)$ average for March 3, to a small negative $(\sim-0.03)$ for March 21, to near zero ( $\sim 0.01)$ for March 29. We present evidence suggesting that a large part of the discrepancies among the three days is due to the different nature of clouds and their non-uniform sampling. Hence, corrections to the grand average broadband absorptance values may be necessary. However, application of the known correction techniques may be precarious due to the sparsity of collocated flux measurements above and below the clouds. Our analysis leads to the conclusion that only March 29 fulfills all requirements for reliable estimates of cloud absorption, that is, the presence of thick, overcast, homogeneous clouds.
\end{abstract}




\section{Introduction}

Recent efforts to resolve the controversial issue of cloudy versus clear sky absorption included two field experiments in the vicinity of the Atmospheric Radiation Measurement (ARM) Program Oklahoma Southern Great Plains (SGP) instrument site. Both field experiments, code-named ARM Enhanced Shortwave Experiment (ARESE) had the common goal of measuring atmospheric absorption explicitly by taking the difference of observed net radiative fluxes at two height levels. ARESE I (which originally was simply called ARESE) took place from September 22 to November 1, 1995. It involved two aircraft fitted with radiometers measuring broadband fluxes from which the absorptance could be obtained for the atmospher:c column between the two collocated aircraft. Results from this experiment were documented extensively in the literature (e.g., Cess et al, 1997; Valero et al., 1997a, b; Zender et al. 1997; Li et al. 1999; O' Hirok et al., 2000). According to some analyses, ARESE I indicated an increase in broadband absorptance with cloud fraction, up to values of 0.31 for overcast skies (Valero et al., 2000, revising the estimates of Cess et al. 1997). The magnitude of absorptance was much higher than that for clear sky $(\sim 0.13)$, in stark disagreement with results from broadband radiation codes implemented in General Circulation Models (GCMs). 
ARESE II was conducted almost five years later, from February 21 through April 15,2000 with the intention to focus on heavy stratus clouds. Due to budgetary constraints only one aircraft was employed, thus significantly departing from the experimental design of ARESE I. The twin Otter flew repeatedly over the Central Facility at an altitude of $\sim 7 \mathrm{~km}$ (when observing clouds) describing a daisy pattern as it measured broadband and spectral shortwave fluxes, while an identical set of instruments was deployed on the ground. The ARESE II ground measurements were complemented by the routine measurements of the ARM operational instrument network. The purpose of ARESE II was to extend the measurements of cloudy sky solar absorption of ARESE I, while addressing the unresolved issues by (1) significantly increasing the number of thick cloud cases; (2) providing more spectral measurements; and (3) where possible, including two or more independent instruments to measure the same component of the solar flux (Ellingson and Tooman, 1999). Overlap with a Cloud Intensive Observation Periods (IOP) was intended for good cloud characterization.

This paper analyzes ARESE II measurements for cloudy days only. In addition to comparisons of cloud broadband absorptances from three different sets of instruments, it investigates sampling and measurement quality issues with the aid of apparent narrowband visible absorptances, and discusses inter-day differences related to the cloud attributes. 


\section{Dataset and cloud absorptance calculation method}

We analyzed data for three days with stratus clouds: March 3, March 21, March 29, 2000.

These days were chosen because they were characterized by the ARESE II field participants as the "best" from an instrument performance and data quality standpoint. Photographs of the cloud decks from the twin Otter can be found on the World Wide Web at http: //armuav.atmos.colostate.edu/uavw00/uavw00.html. Two-dimensional views of cloud location are provided by the Millimiter Cloud Radar (MMCR) (Fig. 1, top panels). Quantitative descriptions of the physical and optical properties of the clouds is obtained from a wide range of surface, airborne, and spaceborn instruments such as surface microwave radiometer (MWR), ceilometer, lidar, Scanning Spectral Polarimeter 2 - SSP2 (Stephens et al. 2000), airborne cloud radar (ACR), Forward Scattering Spectrometer Probe (FSSP) aboard the Citation aircraft, MODIS, GOES- 8 imager, and ETM+ aboard Landsat-7, among others (see other papers in this issue). For example, Fig. 1 (bottom panels) shows the liquid water path (LWP) time series from the ARM archive corresponding to the above-cloud portion of the twin Otter flight for the three days. Cloud description obtained from these instruments can be used as input to radiative transfer simulations that attempt to reproduce the radiometric observations of ARESE II (O' Hirok et al., Powell et al., this issue). In our study, we use ARESE II data from 
instruments that measure radiative fluxes at both the Otter flight level and on the ground. Specifically we use Otter nadir and zenith pointing TSBR (Valero et al., 1982), CM21, CM22 radiometers for broadband, and TDDR (Valero et al., 1989), SSFR (Pilewskie et al., 2000) for spectral measurements, as well as their zenith (upward) pointing counterparts on the ground (when available). The full names of the radiometers used in our analysis and their spectral range are given in Table 1.

The visible or broadband (apparent) absorbed flux for ARESE II is estimated from:

$$
F_{\mathrm{abs}}=\left(F_{\mathrm{dn}}^{\mathrm{o}}-F_{\mathrm{up}}^{\mathrm{o}}\right)-\left(F_{\mathrm{dn}}^{\mathrm{s}}-F_{\mathrm{up}}^{\mathrm{s}}\right)
$$

which can also be written as:

$$
F_{\mathrm{ubs}}=\left(F_{\mathrm{dn}}^{\mathrm{o}}-F_{\mathrm{up}}^{\mathrm{o}}\right)-(1-\alpha) F_{\mathrm{dn}}^{\mathrm{s}}
$$

The first term in parenthesis is the net solar flux at the Otter level (difference between downwelling and upwelling fluxes), and the second term is the net flux at the surface ( $F_{\mathrm{dn}}^{s}$ is the downwelling flux at the surface, $F_{\text {up }}^{s}$ the upwelling flux at the surface, and $\alpha$ is the surface albedo). The Otter net flux is measured by aircraft radiometers facing upward and downward, while the surface net flux is measured by ground (upward facing) and 
tower (downward facing) radiometers. The fractional absorptance $A$ is obtained from ( $1 \mathrm{~b}$ ) by simply dividing by $F_{\text {dn }}^{v}$ :

$$
A=1-R-T(1-\alpha)
$$

so that $R$ and $T$ are the albedo and transmittance of the atmospheric column between ground and aircraft. Time series of $A$ for flight segments when the Otter is above clouds can be obtained by using simultaneous ground and air observations in (1) and (2). The absorbed fluxes or absorptances obtained from the above equations are characterized as apparent because at a particular instant (or for short time averages) they are non-zero even for a perfectly conservative atmosphere. For ARESE II this is due to two main reasons: first, surface and air observations are not in general collocated in space (except when the aircraft flies over the surface instrument), and second, there is often significant net horizontal flux of photons in or out of the atmospheric column due to threedimensional effects, even for perfect collocation (Marshak et al., 1999).

In this paper we use in (1b) fluxes $F^{\mathrm{o}}{ }_{\mathrm{dn}}, F^{\mathrm{o}}{ }_{\mathrm{up}}$, and $F_{\mathrm{dn}}^{\mathrm{s}}$ that are measured by three identical instruments, in other words, measurements from different types of instruments are never combined to calculate absorptance. Thus, from three different triplets of broadband instruments, three different times series of broadband absorptance are obtained, for three days in March 2000. 


\section{Absorptance estimates}

\subsection{Broadband absorption}

Figure 2 summarizes the average values of the fractional flux terms of eq. (2) for the three sets of broadband instruments. Broadband surface albedo comes from tower flux measurements by upward and downward facing pyranometers, as documented in the ARM archive. The closest available in time value is used, although there is not much variability with time; values range from 0.17 to 0.19 for March 3 and 21 , and from 0.15 to 0.17 for March 29. No CM21 ground measurements were taken on March 29, so only the column albedo is shown. Figure 1 shows that clouds were generally thinner on March 3, and thickest on March 21, in agreement with independent GOES-8 retrievals (Minnis et al., this issue). This is consistent with the lower values of column albedo for March 3 compared to March 21 in Fig. 2, despite the higher solar zenith angles of the former day.

Figure 2 also shows that TSBR values of absorptance are quite similar in all three days $(\sim 0.21-0.22)$ and that there is quite good agreement among all three sets of instruments for March 21 and 29, but substantial disagreement on March 3. Most importantly however, notwithstanding the difference between ARESE I and ARESE II in the location and geometric depth of the atmospheric column, Fig. 2 reveals that the ARESE II measurements suggest a much smaller cloud impact on solar absorptance than found in ARESE I (Cess et al., 1999; Valero et al., 2000). 
Fig. 3 shows the time series of apparent broadband absorptance for the three days and the three sets of instruments, as derived from eq. (2). Whenever the three absorptances differ substantially, the source of the discrepancy can be traced back to the Otter fluxes. Fig. 4 shows the net Otter fluxes. The lower absorptance values of CM21 and CM22 on March 3, compared to TSBR, are due to lower values for the downward flux, while upward fluxes agree better for that day (not shown). Surface downward fluxes (and hence net fluxes, since the same surface albedo was used) are also in good agreement, as seen in Fig. 5, thus leaving the downward Otter fluxes as the main culprit for the absorptance discrepancies.

Other papers in this issue ( $\mathrm{O}^{\prime}$ Hirok et al., Powell et al.,) discuss how the measured absorptances of ARESE II compare with radiative transfer simulations for both clear and cloudy skies. As discussed therein, it appears that the gap between model and observed cloudy absorptances has narrowed compared to ARESE I, as has the gap between clear and cloudy sky absorption.

\subsection{Visible absorption}

Estimates of apparent visible absorption can be used to assess the quality of broadband absorptances and correct for sampling effects (Ackerman and Cox, 1980; Valero et al., 1997; Cess et al., 1999; Marshak et al., 1997; Marshak et al., 1999). One of the main issues in ARESE-type derivations of cloud absorption is whether averaging fluxes over 
the entire length of the time series is sufficient to eliminate horizontal flux "contamination" to yield reliable values of true absorptance. This issue is discussed more thoroughly in section 4 . Here, we simply examine whether the $\sim 2 \mathrm{hr}$ averages of apparent visible absorptance are consistent with what we would expect from conservative cloud droplet scattering. Fig. 6 shows the time series of $0.5 \mu \mathrm{m}$ apparent visible absorptance for the three March days, estimated from the Otter and ground TDDR instruments using equations (1) and (2). For surface spectral albedo we use again the closest in time value from the ARM data archive (values range from 0.07 to 0.08 for March 3 and 21, and from 0.04 to 0.06 for March 29). This albedo is estimated at the vicinity of the CART tower as the ratio (at $10 \mathrm{~m}$ ) of MFR upwelling and MFRSR (Table 1) downwelling flux. The three days are quite different, with large positive average apparent absorptance for March 3, negative absorptance for March 21, and close to zero absorptance for March 29. A similar picture emerges at other wavelengths (e.g., $0.675 \mu \mathrm{m}$, not shown). This odd behavior of the visible apparent absorptance time series is in all likelihood not due to errors in the surface flux component, since TDDR surface measurements agree well with other surface instruments such as MFRSR and RSS. However, such agreement cannot be confirmed for the aircraft measurements, at least when TDDR is compared to SSFR, as we will show in a following subsection. 


\section{Sampling issues}

\subsection{Correlations with LWP}

Given the experimental design of ARESE II, an important question is whether the fluxes measured at the ground result from attenuation by the same (in a statistical sense) clouds that largely determine the Otter reflected fluxes as the aircraft describes the daisy pattern.

This condition is more easily satisfied when the clouds are extensive and homogeneous.

The clouds that primarily control the surface fluxes are described quite well (in terms of liquid water path) by the MWR because of its close proximity at the CART site to the surface flux radiometers. This can be seen in scatter plots of downward flux (either broadband or narrowband) vs. LWP (Fig. 7). On the other hand, upward fluxes or atmospheric column albedos generally do not correlate well with the MWR LWP (Fig. 8a) because of the lack of collocation. An additional factor that worsens the correlation with upward fluxes is the larger cloud area viewed by the Otter pyranometers which sample at heights $3-5 \mathrm{~km}$ above cloud top. This effect is more pronounced on March 3 when the Otter is furthest away from the cloud top. Note that the surface downward flux correlation with LWP and the absence of significant correlation with Otter upward (and hence net) flux leads to (deceptive) LWP correlation with absorptance! Such correlation does not indicate any physical processes, but is rather an artifact of surface instrument spatial colocation, and the nature of the sampling design of the experiment. Interestingly, 
on March 21 and 29 (Fig. 8b, c), there is some positive correlation even with the upward Otter flux, suggesting that either the Otter sampled the clouds in a time sequence similar to the MWR (March 21, Fig. 1b) or that cloud were homogeneous to a large degree (March 29, Fig. 1c). Cloud homogeneity on March 29 also explains the physically sound appearance of the visible absorptance time series (Fig. 5) for that day (additional evidence on the superiority of March 29 is provided later). Unsurprisingly, when the Otter passes over the CART site, both Otter upward and surface downward fluxes are correlated with LWP (Fig. 9). Some investigators (e.g., O'Hirok et al., this issue) use only these collocated points in their analysis. Interestingly, the means of broadband and visible absorptance for the collocated measurements are very close to the grand averages of the entire time series quoted earlier. Specifically, the broadband means from collocated measurements are $0.204,0.206$, and 0.219 for March 3, 21, and 29, respectively; the 500 $\mathrm{nm}$ means are $0.093,-0.04$, and -0.003 , i.e., visible absorptance values for March 3 and 21 remain unphysical.

\subsection{Cumulative averages}

Another approach for investigating possible sampling problems is to examine cumulative averages, à la Valero et al. (1997). Fig. 10 shows cumulative averages of the $500 \mathrm{~nm}$ apparent absorptances calculated with the data of the time series arranged in five different ways: in the order the data was collected, with the first $25 \%$ of the data moved to the end 
of the time series, with the first $50 \%$ moved to the end, with the first $75 \%$ moved to the end, and, finally, backwards. A measure of the uniformity of sampling is the proximity of the five curves after a substantial (e.g. $\sim 600$ ) number of measurements has been included in the average, while asymptotic approach to the endpoint is a necessary condition for adequate length of the time series. March 29 displays the most asymptotic behavior, while March 3 does not show any at all. March 29 is also the day with the closest proximity among the five curves. Another way of presenting the results of Fig. 10 is shown in Fig. 11 where we plot the standard deviation of the five cumulative averages as a function of the fraction of the total number of points. This figure gives an idea of how closely the grand average is approached when only a fraction of the points is averaged. Better sampling is implied for the curve that remains the closest to the abscissa and asymptotically approaches zero the earliest. In this representation, March 29 seems again to be superior to the other two. The preeminence of March 29 is consistent with other results we have presented so far, as well as results presented in the following subsections.

\subsection{TDDR and SSFR comparisons}

The spurious values of TDDR apparent visible absorptance naturally require further investigation. The simplest thing would be to compare with visible apparent absorptance values from SSP2 and SSFR. Unfortunately, the datastream processing for the former instrument was not completed at the time this paper was written (McCoy, personal 
communication, 2001), while the unavailabiltiy of surface measurements for the latter prohibited the calculation of SSFR apparent visible absorptances. We therefore restrict our comparisons to Otter TDDR and SSFR fluxes only.

Figure 12 shows the downward and upward $500 \mathrm{~nm}$ fluxes for both instruments for all three days. Agreement is in general better for the upward fluxes, and actually particularly good for March 21. There is significant separation in the downward fluxes, with features in the SSFR time series indicating uncorrected navigational effects. Taking the difference between the upward and downward fluxes of Fig. 12 shows that SSFR net fluxes are smaller than TDDR for March 3, but greater for March 21 and 29. Had the SSFR downwelling surface flux been similar to the other ground instruments (TDDR, MFRSR, RSS), its grand average visible absorptances would have been lower for March 3 and higher for March 21 and 29. This would definitely improve the March 3 and March $21500 \mathrm{~nm}$ absorptance averages, since it would push them towards more realistic values, but the impact on March 29 absorptances is unclear. Hence, despite the erratic nature of the Otter SSFR flux time series, the average values seem to be realistic.

TDDR and SSFR $500 \mathrm{~nm}$ spectral fluxes can also be compared via their relationship to the visible broadband flux which can be approximately obtained by subtracting TSBR and FSBR measurements (see Table 1). Figure 13 shows the ratio of the TSBR-FSBR difference over the $500 \mathrm{~nm}$ fluxes for both TDDR and SSFR. Only March 21 and 29 are shown in the figure because for March 3 the upward FSBR fluxes were not available. 
Conventional knowledge says that both the visible and narrowband $500 \mathrm{~nm}$ flux would interact with the cloud in the same manner. One would therefore expect that their ratio would: a) remain constant with time, and b) be similar for the upward and downward fluxes. These expectations seem to be satisfied for March 29, particularly for the TDDR (the SSFR deviations seem to originate again from inadequate navigational corrections).

March 21 however, seems to characterized by two anomalies: first, the TDDR downward ratio shows a tendency to increase with time; and second, the upward and downward ratios differ significantly for both instruments. We have no yet found an explanation for these anomalies.

Finally, one can calculate the broadband visible absorptance from the net flux difference of ground and Otter TSBR-FSBR differences. The grand average values for cloudy conditions are 0.04 for March 21 and 0.03 for March 29. These are reasonable values for the column between the aircraft and the ground, but are obtained by taking 7 flux differences, and are thus more susceptible to errors than the $500 \mathrm{~nm}$ absorptances. Other papers in this issue (e.g. O'Hirok et al.) examine the quality of broadband visible absorptances and compare them with simulated values.

\subsection{Analysis by flight leg}

Beyond the grand daily averages, conventional wisdom would suggest that even averaging over a flight leg should eliminate a large amount of horizontal fluxes. This is 
because in most cases the time period between aircraft turns, i.e., the duration of a flight leg is quite long; typical flight legs last $\sim 500 \mathrm{sec}$, a time period durinh which the Otter aircraft covers distances of a few tens of kilometers. An analysis by flight leg may shed more light on the stability of the measurements, something we have already an idea about from Fig. 3-6. Fig. 14 shows the mean TSBR broadband absorptances per flight leg for all three days. March 21 and 29 have a much tighter range of values suggesting smaller sampling effects than March 3 for which the first and last leg have absorptances that differ by a factor larger than two. Fig. 15 is the $500 \mathrm{~nm}$ TDDR counterpart. In this case there are distressing features for all three days, each having flight legs where the absorptance takes unexpected values considering the large spatial domains corresponding to each flight leg (flight legs with only few data were discarded, so our shortest flight leg has 145 continuous seconds of data). This brings up again the important question of whether the surface instruments and the aircraft sampled the same clouds statistically; it seems that at the flight leg scale the answer is negative. Figure 16 provides the standard deviation of the flight leg averages as error bars superimposed on the column bars depicting the means of the flight leg averages. The latter are very close to the TSBR means of Fig. 2, the small differences being due to the omission of the data corresponding to flight legs of very short duration. The March 3 standard deviation is the largest, as expected. 


\subsection{Conditional sampling}

Conditional sampling is a powerful technique for obtaining true absorption estimates without horizontal averaging (Marshak et al. 1999), thus increasing the number of absorption data obtained from a single experiment. The principal idea is to select (i.e., sample) the broadband absorptance values at time instances where (i.e., the condition) a narrow band apparent absorptance is close to its true value (assumed to be known). This narrow band is usually a subinterval of the visible portion of the spectrum where cloud scattering is believed to be conservative, i.e., true absorption $A_{v}{ }^{\prime}$ can only be due to gaseous absorption and aerosols. It can be assumed that the value of true absorption is obtained from averaging the apparent absorptance time series for this narrow band, i.e., $A_{v}{ }^{\prime}=\left\langle A_{v}\right\rangle$. Narrow bands around $500 \mathrm{~nm}$ have been used in the past (Marshak et al., 1999). The relevant question then is: can conditional sampling be applied to ARESE II measurements?

It is immediately apparent that there are two problems: first, the $\left\langle A_{v}\right\rangle$ values of absorptance at visible wavelengths as inferred from TDDR are questionable since they differ significantly among the three days and are outside their physically expected bounds for the first two days. Hence, the value of true visible $(0.5 \mu \mathrm{m})$ absorptance for ARESE II cannot be determined with certainty, although we believe that it is close to the March 29 value. Alternatively, modeled values of visible absorptance could be used for $\left\langle A_{\curlyvee}\right\rangle$, but this does not help much when the quality of the entire observed time series is 
questionable. Second, given the single-aircraft design of ARESE II, an apparent visible absorptance close (i.e, within $\pm \varepsilon$, where $\varepsilon$ is small) to the true visible absorptance at a particular instance, does not necessarily guarantee that there was little or no horizontal flux at the corresponding location. The reason is that aircraft and surface flux collocation is the exception rather the rule. In other words, the condition $\left.\left\langle A_{v}\right\rangle-\varepsilon \leq A_{v}(\mathrm{t}) \leq<A_{v}\right\rangle+\varepsilon$ is satisfied not only when the horizontal fluxes are small, but also fortuitously

Despite these caveats, we can still assess whether conditional sampling provides any new information about broadband absorptance for the three selected days of ARESE II. Here, we compare the mean broadband absorptance of conditionally sampled points with the average broadband absorptance of the entire time series $<A_{\mathrm{bb}}>$. This can be done for various $\varepsilon$ values around $A_{\mathrm{v}}{ }^{\mathrm{l}}$. We select $A_{\mathrm{v}}{ }^{\prime}=0$ for all days based on the TDDR result $<A_{v}>\approx 0$ for March 29, and $\varepsilon=0.03$. From Fig. 6 we see that on March 3 there are very few points within $A_{v}{ }^{\prime} \pm \varepsilon= \pm \varepsilon$. It comes therefore as no surprise that the difference from the grand average absorptance $\left\langle A_{b b}>\right.$ is large $(0.15$ vs 0.20$)$. Because of the doubtful quality of the March $3500 \mathrm{~nm}$ absorptance time series, this may very well be a meaningless result. For March 29, the conditionally sampled absorptance and $\left\langle A_{\mathrm{bh}}\right\rangle$ are almost identical $\sim 0.225$, while for March 21 they are very close $(0.22$ vs. 0.21$)$, which is encouraging. From the above we conclude that we can be somewhat confident for March 21 and 29 grand averages of broadband absorptance. 


\subsection{Absorptance time series correction}

In addition to conditional sampling, modifications to the "Ackerman-Cox" (Ackerman and Cox, 1980) correction method of three-dimensional cloud effects, such as those suggested by Marshak et al. (1997) and Cess et al. (1999), can be used on the ARESE II broadband absorptance time series. These methods, by design, do not change the grand average values of absorptance, but intend to improve the instantaneous values. We implement here the correction described by Cess et al. (1999):

$$
A_{\mathrm{bb}}{ }^{c}=A_{\mathrm{bh}}-c\left(A_{\mathrm{v}}-<A_{v}>\right)
$$

$A_{v}$ is the $500 \mathrm{~nm}$ apparent absorptance as before and $<>$ stands for time average. $c$ is the slope of the regression fit of $A_{\mathrm{bb}}$ vs. $A_{\mathrm{v}}$ (Fig. 17). The premise of the method is that broadband and $500 \mathrm{~nm}$ absorptances are correlated (which is confirmed by Fig. 17 and 18), and that the correlation is mainly because of three-dimensional radiative effects. Equation (3) is an extension of the Marshak et al. (1997) correction $A_{\mathrm{bb}}{ }^{\mathrm{c}}=A_{\mathrm{bb}}-\mathrm{c} A_{\mathrm{v}}$ which assumes $\left\langle A_{\mathrm{v}}\right\rangle=0$ for $500 \mathrm{~nm}$. Ackermann and Cox (1980) initially suggested $A_{\mathrm{bb}}{ }^{\mathrm{c}}$ $=A_{\mathrm{bb}}-A_{\mathrm{v}}$, i.e., that the $500 \mathrm{~nm}$ (or any conservative) band have the same horizontal flux as the broadband measurement. However, Fig. 17 clearly indicates that $c \neq 1$ (we actually find values of $c$ quite close to the 2/3 slope reported by Marshak et al., 1997 and Cess et al., 1999), and we have already seen that in general $\left\langle A_{v}>\neq 0\right.$, so the more general eq. (3) 
appears to be the most appropriate. In short, eq. (3) attempts to remove for each point (instant) the broadband horizontal flux by using its relationship with the $500 \mathrm{~nm}$ horizontal flux.

Figure 18 shows the corrected broadband absorptance time series for all three days. The tightening of the time series after the correction has been applied is quite remarkable. The March 3 corrected absorptance still has two spikes at $\sim 17.9$ and 18.9 GMT. Around these times the correlation between $A_{\mathrm{b}}$ and $A_{\mathrm{v}}$ breaks down (group of points separated from the main cluster in Fig. 17a) for unknown reasons, and the correction (3) does not work optimally. March 21 is even more complicated. The three different segments of the time series as determined by the data gap around 17.4 and 18.0 GMT are also characterized by different cloud types (Fig. 1b, top) resulting in different correlations between visible and broadband flux. Fitting a single regression line to the data of Fig. 17b would give a meaningless slope, so we use in eq. (3) the average of the three individual slopes, i.e., a value of $\sim 0.8$. This approximation is the main reason for the two dips that appear in the $A_{\mathrm{bb}}{ }^{c}$ time series, around 16.85 and $17.7 \mathrm{GMT}$. The fit corresponding to the mean slope is not representative of the broadband and $500 \mathrm{~nm}$ correlations at these times when cloud structure is complicated (upper level cloud, above the Otter, at $\sim 16.85$ GMT, complex cloud top structure and neighboring upper level clouds at $17.7 \mathrm{GMT}$, according to Fig. 1b). Dips in the original absorptance series themselves appear only for TSBR and CM22 (Fig. 3). It is disconcerting that clouds above the Otter can affect the estimates of 
absorptance for the column below. Our explanation is that an overlying small cloud affects the downward Otter flux much more than the upward flux which results from contributions of reflected radiation from a far larger area of the cloud below. This is confirmed by inspection of the TSBR and CM22 upward and downward fluxes (not shown). If the surface fluxes are insensitive to the upper cloud (as they should be) the absorptance drops by responding to the drop in the Otter net flux. The magnitude of the drop depends on the details of the sensitivity of each instrument to reflected (upward) radiation from regions far away from the sub-aircraft point, and the amount of timeaveraging in the measurements.

In contrast with March 3 and 21, the correction by eq. (3) does not encounter any problems for March 29, producing a distinctively flat absorptance time series (Fig. 18c). The more homogeneous nature of the cloud produces unambiguous correlations between $500 \mathrm{~nm}$ and broadband absorptance (Fig. 17c), resulting in the removal of most horizontal fluxes by eq. (3). In other words, the variability in the March 29 broadband absorptance time series (Fig. 3) is largely due to three-dimensional effects and not a manifestation of the natural variability of the cloud (column) absorption. 


\section{Summary and discussion}

We have analyzed a wide range of ARESE II measurements in order to establish whether robust estimates of cloud shortwave absorptance can be obtained. Our approach was to examine inter-instrument differences, consistency of broadband and visible measurements, and adequacy of sampling. The main conclusion is that of the three "best" overcast days of ARESE II, only one (03/29/00) seems to satisfy the three most important requirements of an ideal ARESE II cloud system (Ellingson and Tooman, 1999), i.e, to be thick, overcast (extensive), and horizontally homogeneous. These requirements would help overcome the sampling limitations of the experiment stemming from the availability of a single aircraft. The March 3 cloud deck, as revealed by photographs taken by the Otter does occasionally present patches of clear sky, and is not thick enough, i.e., it seems to fail two out of three condiions. Moreover, the greater distance of the aircraft from the cloud top amplifies the non-local nature of the Otter upward (reflected) fluxes. The March 21 clouds are extensive and thick, but they present a complex structure, thus failing the requirement of homogeneity. As a result, the degree to which the average broadband absorptance approaches the true average cloud absorptance for these two days cannot be assessed with the same confidence as for March 29, when clouds satisfy all three requirements. A number of data analysis methods, such as cumulative averaging, 
correlation between narrowband visible and broadband absorptances, conditional sampling, and horizontal flux corrections work reasonably well for March 29.

Some specific highlights of our results are the following:

- Broadband absorptance for the three overcast ARESE II days is 0.21-0.22 for TSBR, significantly lower than the overcast estimates of ARESE I. The March 29 value of 0.22 is the most robust, followed by March 21 , while the value for March 3 should be considered uncorrected for three-dimensional effects. In terms of $\mathrm{W} \mathrm{m}^{-2}$, the largest value of TSBR broadband absorptance is for March 29, $231 \mathrm{Wm}^{-2}$, while values for March 3 and 21 , were $197 \mathrm{Wm}^{-2}$ and $211 \mathrm{Wm}^{-2}$, respectively. These agree well with the values reported by Powell et al. (2001).

- Systematically smaller absorptance is inferred from CM21 and CM22 for March 3, one of the two days where both Otter and ground CM21 measurements were available. This is mainly due to the smaller Otter net fluxes which in turn result from smaller downwelling fluxes. The reason for the disagreement in the downwelling fluxes is unknown.

- Most instrument cross-comparisons predictably give larger differences for Otter downwelling fluxes which are more sensitive to navigational effects.

- Application of conditional sampling is difficult to justify for ARESE II given the curious behaviour of the visible absorptance time series on March 3 and 21 and the 
sampling nature of a single aircraft experiment; corrections à la Cess et al. (1999) seem, however, to be quite successful.

- The ARESE II sampling strategy creates fictitious correlations between instantaneous values of MWR LWP and apparent absorptances. This is due to the much stronger correlations of surface net fluxes with LWP compared to Otter net flux - LWP correlations.

- Clouds above the aircraft affect estimates of absorptance due to their disproportionate effect on upwelling and downwelling fluxes. This is because the aircraft flies too far above the cloud top.

From the above we conclude that although much progress in the understanding of ARESE II measurements has been made, further investigation of unexplained discrepancies and their relationship to the properties of the cloud systems and/or the shortcomings of the experimental design would be useful. From our perspective, it is particularly important to understand inter-instrument differences of visible fluxes and the relationship between visible and broadband fluxes. The reconstruction of the cloud fields from observations, and the radiative transfer modeling that other investigators are undertaking will be very useful for this purpose. 
Acknowledgements

Data was obtained from the Atmospheric Radiation Measurement (ARM) Program sponsored by the U. S. Department of Energy, Office of Energy Research, Office of Health and Environmental Research, Environmental Sciences Division. We would like to thank F. P. J. Valero, T. P. Tooman, S. Asano, and P. Pilewskie, for sharing with us information about the instruments the operated during ARESE II and their respective datasets. This research was supported by the Office of Biological and Environmental Research of the U. S. Department of Energy (under grant No. xxx) as part of the Atmospheric Radiation Measurement Program. 


\section{References}

Ackerman, S. A., and S. K. Cox, Aircraft observations of shortwave fractional absorptance of non-homogeneous clouds. J. Appl. Meteor., 20, 1510-1515, 1980.

Cess, R. D., M. H. Zhang, Y. Zhou, X. Jing, and V. Dvortsov, Absorption of solar radiation by clouds: Interpretations of satellite, surface and aircraft measurements. J. Geophys. Res., 101, 23299-23309, 1996.

Cess, R. D., M. H. Zhang, F. P. J. Valero, S. K. Pope, A. Bucholtz, B. Bush, C. S. Zender, J. Vitko, Absorption of solar radiation by the cloudy atmosphere: Further interpretation of collocated aircraft measurements. J. Geophys. Res., 104, 2059$2066,1999$.

Ellingson, R., and T. P. Tooman (ed.), Science and experiment plan for the second Atmospheric Radiation Measuremeent Enhanced Shortwave Experiment, available at http://armuav.atmos.colostate.edu/science_plans/s2000.pdf, 1999.

Li, Z., Trishchenko, A. P., Barker, H. W., Stephens, G. L., Partain, P., Analyses of Atmospheric Radiation Measurement (ARM) program's Enhanced Shortwave Experiment (ARESE) multiple data sets for studying cloud absorption, J. Geophys. Res., 104, 19,127-19,134, 1999.

Marshak, A., Davis, A., Wiscombe, W., Cahalan, R., Inhomogeneity effects on cloud shortwave absorption: two-aircraft simulations, J. Geophys. Res., 102, 16619$16637,1997$. 
Marshak, A., W. J. Wiscombe, A. Davis, L. Oreopoulos, and R. F. Cahalan, On the removal of the effect of horizontal fluxes in two-aircraft measurements of cloud absorption. Q. J. Roy. Met. Soc. 125, 2153-2170, 1999.

O' Hirok, W., C. Gautier, and P. Ricchiazzi, Spectral signature of column solar radiation absorption during the Atmospheric Radiation Measurements Enhanced Shortwave Experiment (ARESE), J. Geophys. Res., 105, 17471-17480, 2000.

Pilewskie, P., M. Rabbette, R. Bergstrom, J. Marquez, B. Schmid, and P. B. Russell, The discrepancy between measured and modeled downwelling solar irradiance at the ground: Dependence of water vapor. Geophys. Res. Lett., 27, 137-140, 2000.

Powell. D. M., R. T. Marchand, and T. P. Ackerman, An analysis of cloud absorption during ARESE II (Spring 2000). Proc. of $11^{\text {th }}$ ARM Science Team Meeting, http://www.arm.gov/docs/documents/technical/conf_0103/powell-dm.pdf, 2001.

Stephens, G. L., R. F. McCoy, R. B. McCoy, P. Gabriel, P. Partain, S. D. Miller, A multipurpose Scanning Spectral Polarimeter (SSP): Instrument description and sample results, J. Atmos. Ocean. Techn., 17, 616-627, 2000.

Valero, F. P. J., W. J. Y. Gore, and P. M. Giver, Radiative flux measurements in the troposphere, Appl. Opt., 21(5), 831-838, 1982.

Valero, F. P. J., T. P. Ackerman, and W. J. Y. Gore, The effects of the Arctic haze as determined from airborne radiometric measurements during AGASP II, J. Atmos. Chem., 9, 225-244., 1989. 
Valero, F. P. J., R. D. Cess, M. Zhang, S. K. Pope, A. Bucholtz, B. C. Bush, and J. Vitko, Jr., Absorption of solar radiation by the cloudy atmosphere: Interpretations of collocated aircraft measurement, J. Geophys. Res., 102, 29917-29927, 1997a.

Valero, F. P. J., A. Bucholtz, B. C. Bush, S. K. Pope, W. D. Collins, and P. Flatau, Atmospheric Radiation Measurements Enhanced Shortwave Experiment (ARESE): Experimental and data details, J. Geophys. Res., 102, 29929-29937, $1997 \mathrm{~b}$.

Valero, F. P. J.. P. Minnis, S. K. Pope, A. Bucholtz, B. C. Bush, D. R. Doelling, W. L. Smith Jr., and $\mathrm{X}$. Dong, Absorption of solar radiation by the atmosphere as determined using satellite, aircraft, and surface data during the Atmospheric Radiation Measurement Enhanced Shortwave Experiment (ARESE), J. Geophys. Res., 105, 4743-4758, 2000.

Zender, C. S., B. C. Bush, S. K. Pope, A. Bucholtz, W. D. Collins, J. T. Kiehl, F. P. J. Valero, and J. Vitko Jr., Atmospheric absorption during the Atmospheric Radiation Measurement (ARM) Enhanced Shortwave Experiment (ARESE), J. Geophys. Res., 102, 29901-29915, 1997. 


\section{List of tables}

Table 1 Instruments used in this study

\begin{tabular}{|c|c|c|}
\hline Instrument & Mentor & What is measured \\
\hline $\begin{array}{l}\text { TSBR, Total Solar } \\
\text { Broadband Radiometer }\end{array}$ & Valero & Brodband fluxes $0.2-3.9 \mu \mathrm{m}$ \\
\hline $\begin{array}{l}\text { FSBR, Fractional Solar } \\
\text { Broadband Radiometer }\end{array}$ & Valero & $\begin{array}{l}\text { Broadband fluxes } 0.68-3.3 \\
\mu \mathrm{m}\end{array}$ \\
\hline $\begin{array}{l}\text { TDDR,Total Direct Diffuse } \\
\text { Radiometer }\end{array}$ & Valero & $\begin{array}{l}\text { Narrowband visible fluxes } \\
\text { ( } 7 \text { channels) }\end{array}$ \\
\hline $\begin{array}{l}\text { SSFR, Solar Spectral Flux } \\
\text { Radiometer }\end{array}$ & Pilewskie & $\begin{array}{l}\text { Continuous spectral fluxes } \\
0.3-2.5 \mu \mathrm{m}\end{array}$ \\
\hline $\begin{array}{l}\text { CM21, Kipp \& Zonen } \\
\text { pyranometer }\end{array}$ & Asano & $\begin{array}{l}\text { Broadband fluxes } 0.3-2.8 \\
\mu \mathrm{m}\end{array}$ \\
\hline $\begin{array}{l}\text { CM22, Kipp \& Zonen } \\
\text { pyranometer }\end{array}$ & Tooman & $\begin{array}{l}\text { Broadband fluxes } 0.2-3.6 \\
\mu \mathrm{m}\end{array}$ \\
\hline $\begin{array}{l}\text { MFR, Multi-filter } \\
\text { radiometer }\end{array}$ & Schmelzer & $\begin{array}{l}\text { Narrowband solar fluxes at } \\
\text { the } 6 \text { solar MFRSR bands }\end{array}$ \\
\hline $\begin{array}{l}\text { MFRSR, Multi-filter } \\
\text { Rotating Shadowband } \\
\text { Radiometer }\end{array}$ & Schmelzer & $\begin{array}{l}\text { Narrowband solar fluxes at } \\
6 \text { solar bands below } 1 \mu \mathrm{m}\end{array}$ \\
\hline $\begin{array}{l}\text { RSS, Rotating Shadowband } \\
\text { Spectrometer }\end{array}$ & Michalsky & $\begin{array}{l}\text { Spectral fluxes, } 0.35-1.075 \\
\mu \mathrm{m}\end{array}$ \\
\hline $\begin{array}{l}\text { MWR, Microwave } \\
\text { Radiometer }\end{array}$ & Morris & $\begin{array}{l}\text { Water Vapor, Cloud liquid } \\
\text { water path }\end{array}$ \\
\hline
\end{tabular}




\section{Figure captions}

Figure 1 Two-dimensional cloud reflectivity from the Millimeter Cloud Radar, MMCR (top) and Liquid Water Path, LWP at the CART site from the Microwave Radiometer, MWR (bottom) for the time period when the Otter was flying above the cloud deck. (a)

March 3; (b) March 21; (c) March 29. The gap in the March 3 MMCR display is not due to the absence of clouds, but due to the lack of data.

Figure 2 Above-cloud flight averages of all components of the fractional flux energy budget (Eq. 2) for the atmospheric column defined by the surface and the Otter aircraft. Three days and three sets of instruments are shown. Only albedo at the Otter level $(\sim 7$ $\mathrm{km}$ ) is shown for CM21 on March 29, because no CM21 ground data were available.

Figure 3 Time series of apparent broadband absorptance for the atmospheric column defined by the surface and the aircraft flying above clouds. The same three days and three sets of instruments as in Fig. 2 are included in the plots. No CM21 absorptance was calculated for March 29, because of the unavailability of ground data.

Figure 4 Time series of net broadband flux (down minus up) at the Otter level $(\sim 7 \mathrm{~km})$ for the same three days and three sets of instruments as in Fig. 2 and 3. Discrepancies among the instruments are mostly due to discrepancies in downward fluxes. 
Figure 5 Time series of net downward fluxes $(1-\alpha) F_{\mathrm{dn}}^{\mathrm{s}}$ for three ARESE II days and three sets of instruments corresponding to the above cloud flight segment. There were no CM21 measurements available on March 29.

Figure 6 Time series of TDDR channel $1(0.5 \mu \mathrm{m})$ apparent visible absorptance for three cloudy ARESE II days. The means of the time series are shown in parenthesis in the legend.

Figure 7 Broadband surface TSBR flux, vs. LWP from the MWR, for the three March days, when TSBR fluxes are averaged at the temporal resolution of the MWR data.

Figure 8 Broadband Otter TSBR albedo, vs. LWP from the MWR, for the three March days, when TSBR fluxes are averaged at the temporal resolution of the MWR data.

Figure 9 Broadband TSBR downward fluxes (left column) and upward fluxes (right column) vs. LWP from MWR for data points corresponding to aircraft overpass over the CART site (aircraft is within a $0.02^{\circ}$ square centered at CART).

Figure 10 Cumulative average of TDDR channel $1(0.5 \mu \mathrm{m})$ apparent absorptance for 5 different ways of ordering the data (explained in the text). Performed for the 3 days analyzed in this paper.

Figure 11 Standard deviation for all three days of the five different cumulative averages of Fig. 10 as a function of the fraction of the total time series length (total number of points in Fig. 10). 
Figure 12 Comparison between Otter SSFR and TDDR $500 \mathrm{~nm}$ upward and downward spectral fluxes for three ARESE II days studied in this paper. March 3 is on top, March 29 at the bottom.

Figure 13 Ratio of "visible" (TSBR-FSBR) over $500 \mathrm{~nm}$ TDDR or SSFR fluxes at the Otter level for March 21 (top) and March 29 (bottom).

Figure 14 Broadband apparent absorptance per flight leg for the three ARESE II days analyzed.

Figure 15 As in Figure 13, but for apparent $500 \mathrm{~nm}$ absorptance. The number of legs is different from Fig. 13 for March 21, due to the availability of TDDR measurements at time instances where TSBR data where not available.

Figure 16 Mean and standard deviation (depicted as error bars) of the data presented in Fig. 13 and 14.

Figure 17 TSBR apparent broadband absorptance versus TDDR $500 \mathrm{~nm}$ apparent absorptance for March 3 (top), March 21 (middle), and March 29 (bottom). The lines are least square fits with the slope values given in the legend. Three separate fits were performed for March 21, corresponding to the three data segments (separated by wide gaps) shown in Fig. 17.

Figure 18 Time series of apparent absorptance for TDDR $500 \mathrm{~nm}$ channel, apparent TSBR broadband absorptance (as in Fig. 3), and "corrected" TSBR absorptance according to the method described in $\$ 4.7$. The three days are ordered as in Fig. 16. 

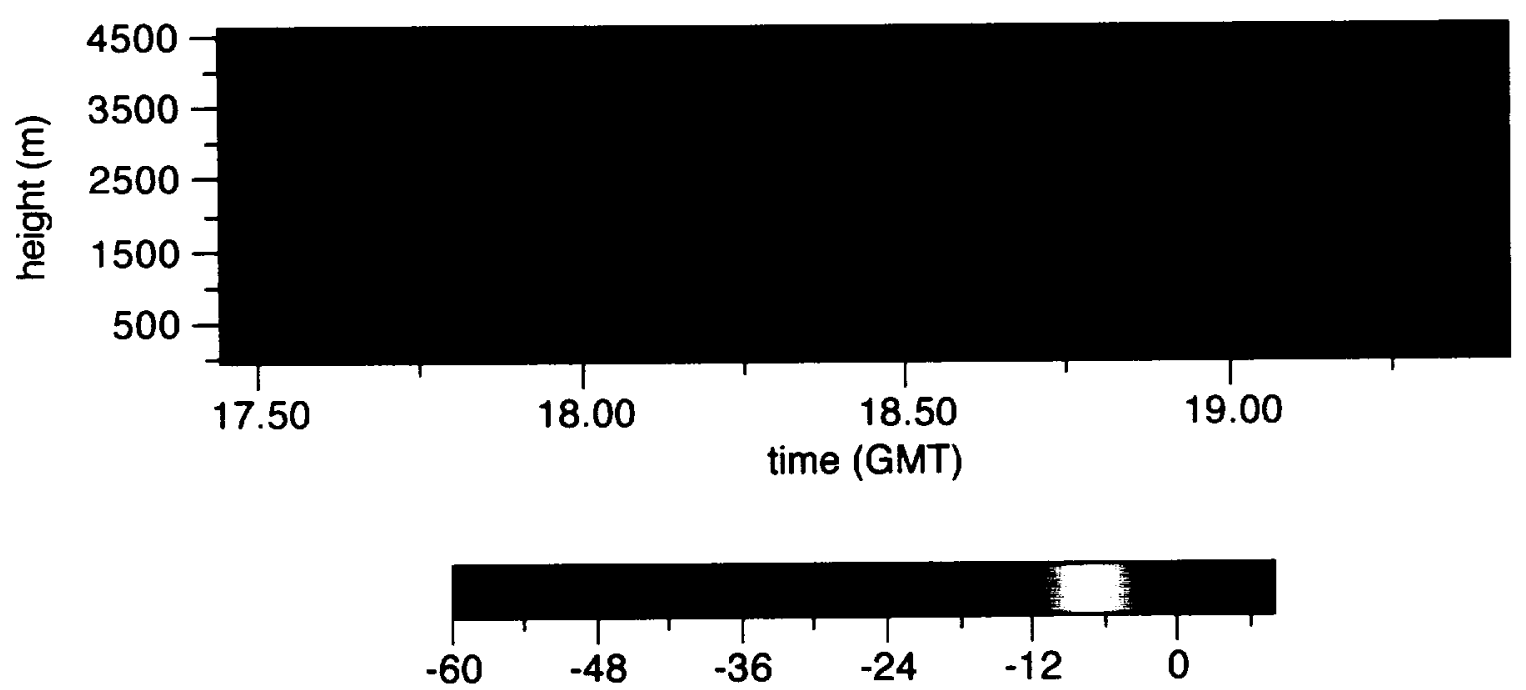

reflectivity ( $d B Z$ )

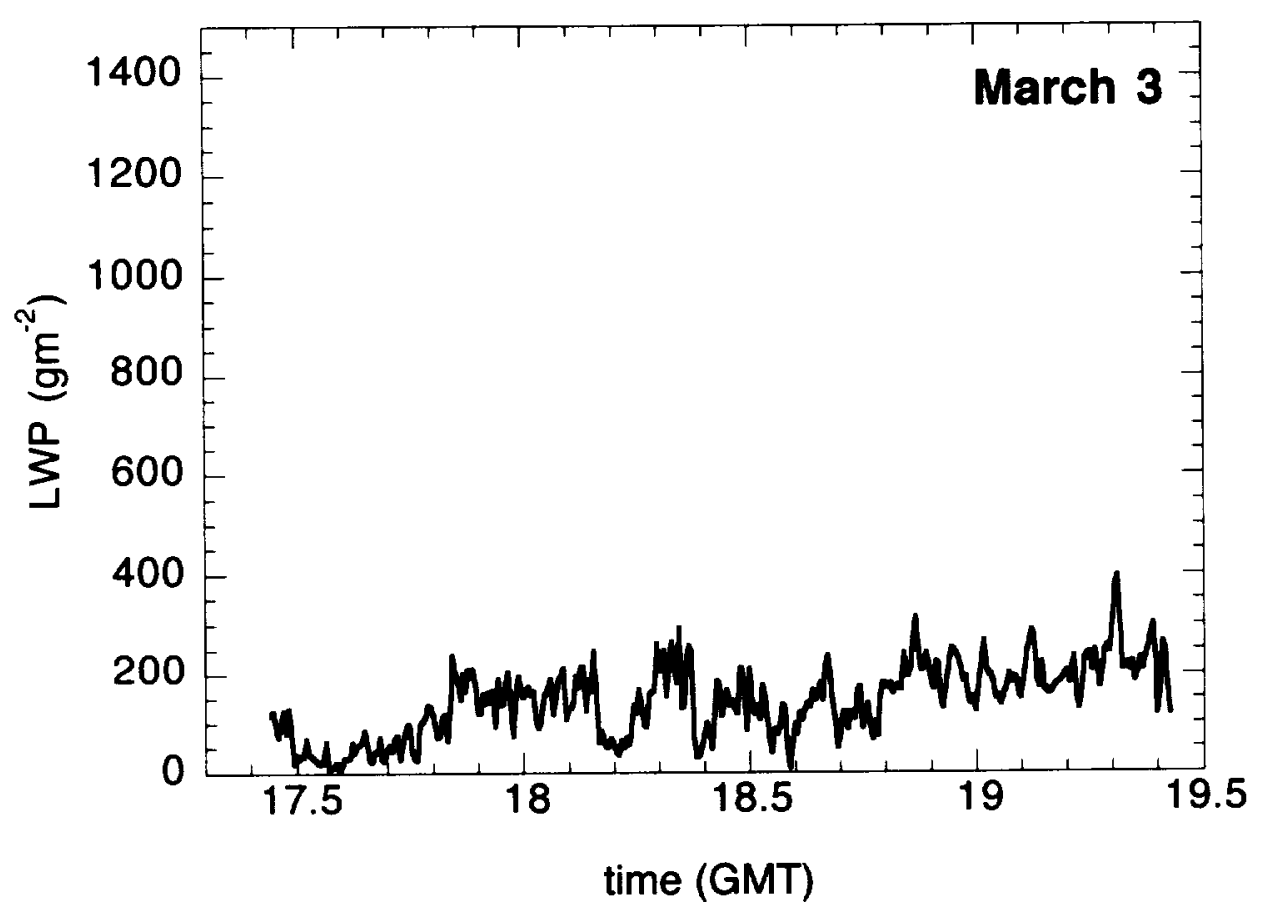

Figure 1a 
1 

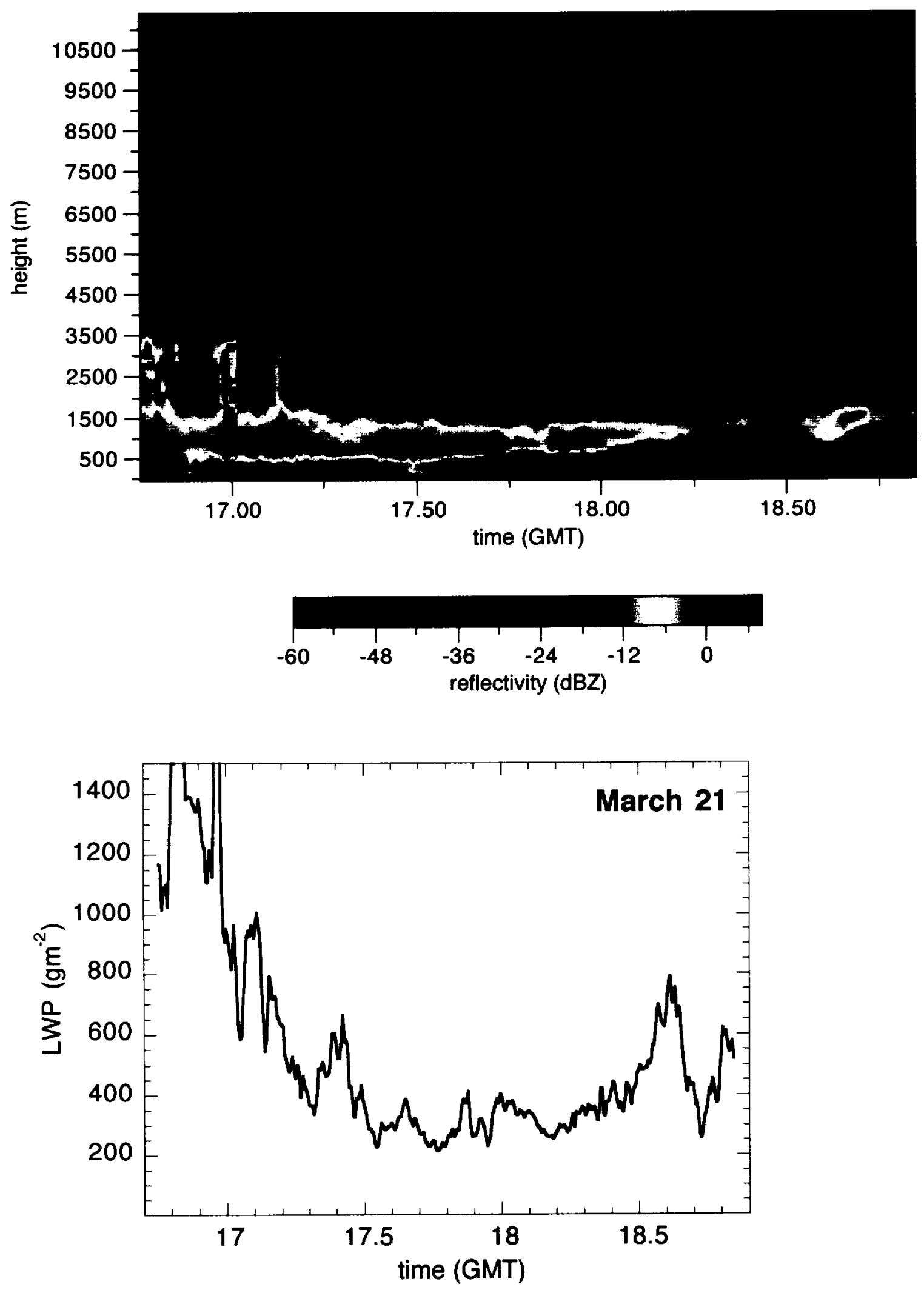

Figure 1b 
1 

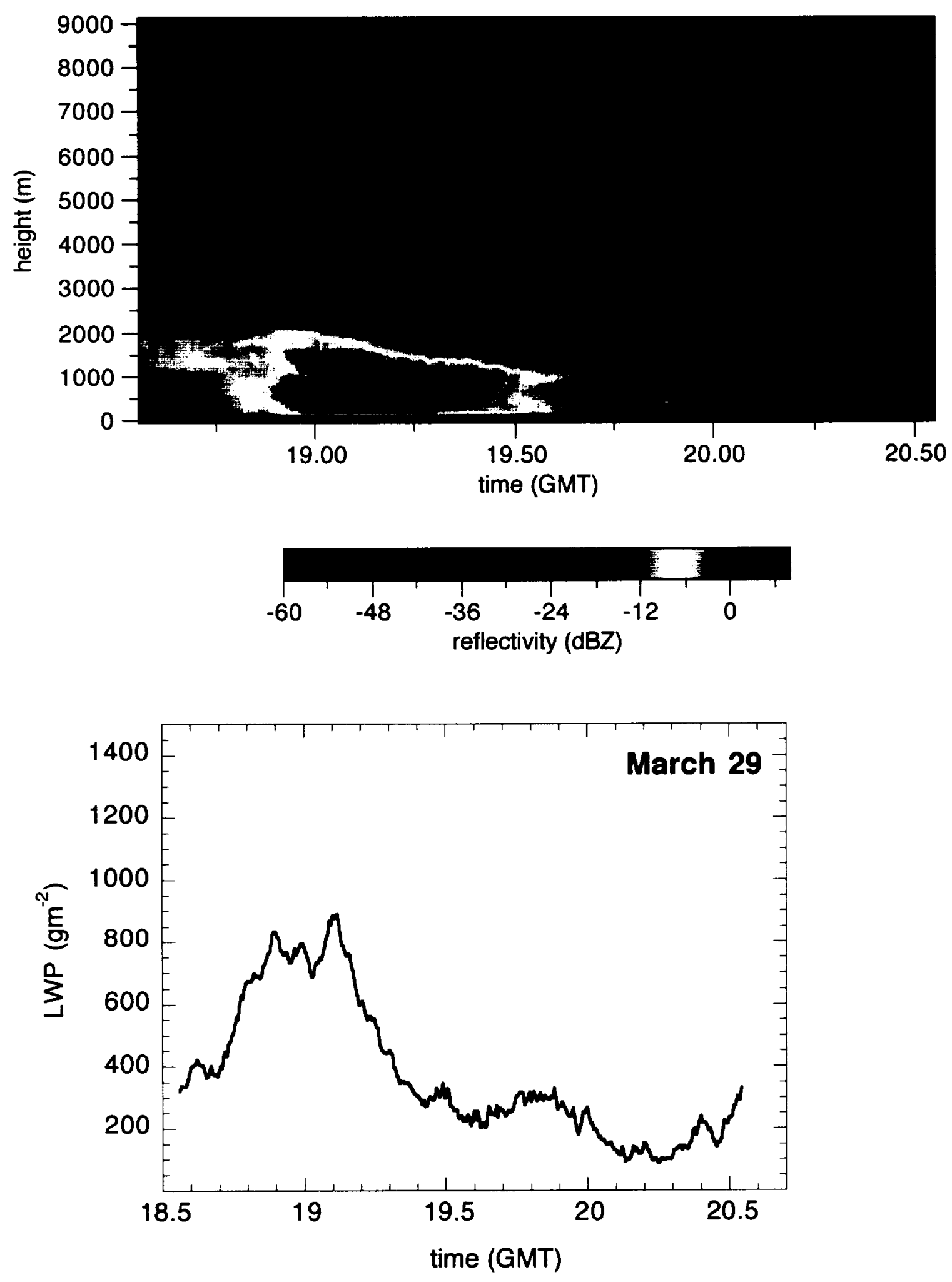

Figure 1c 


$$
1
$$




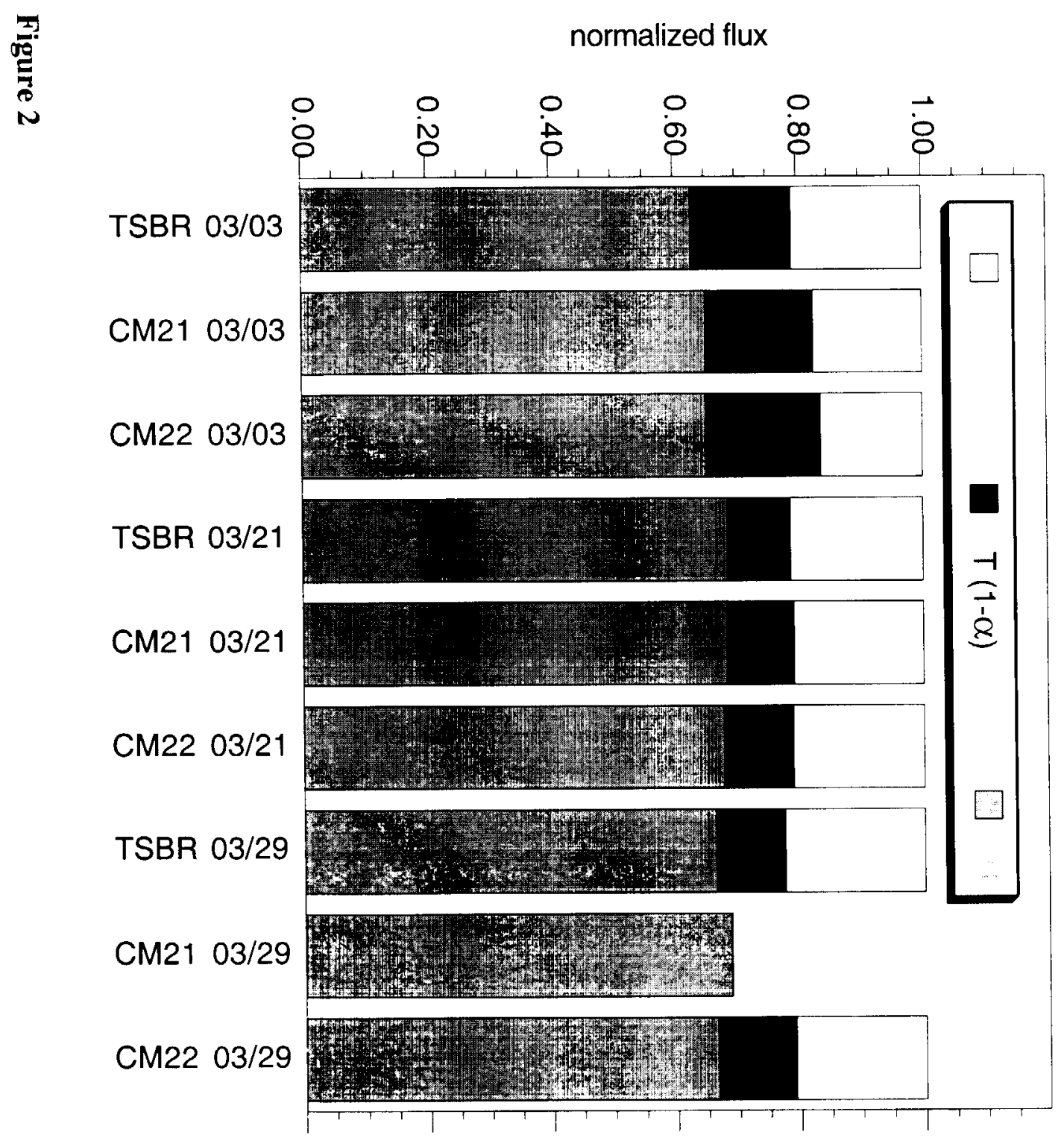


1 

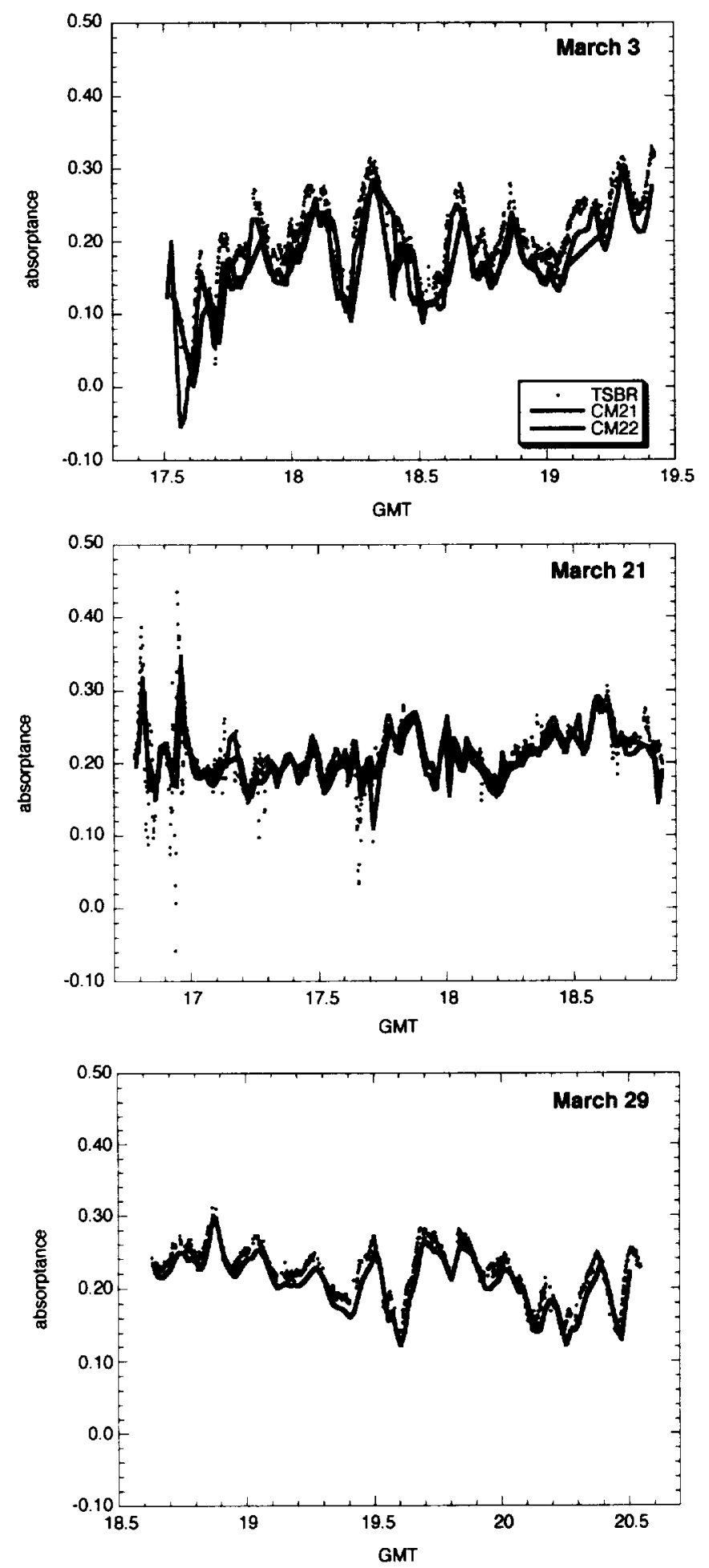

Figure 3 

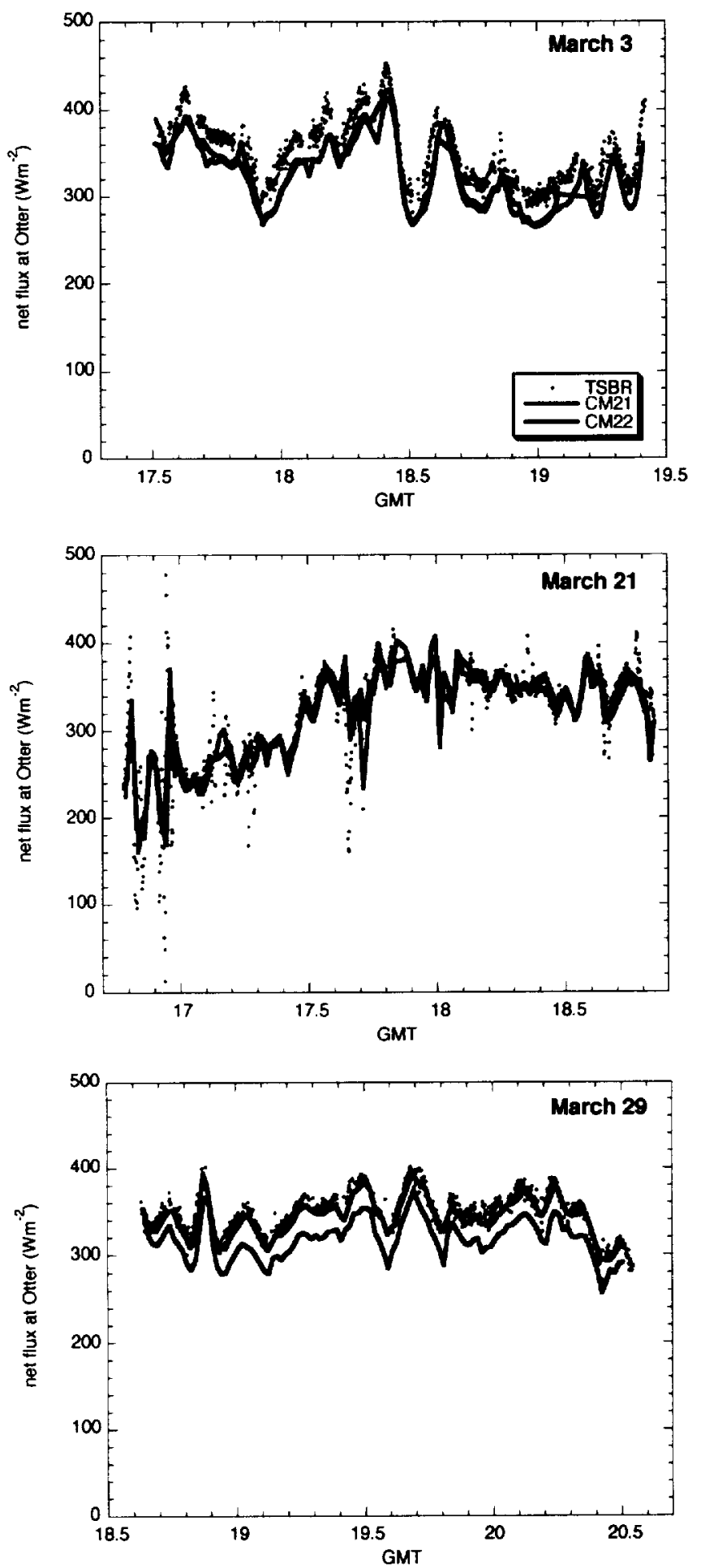

Figure 4 
1 
羿

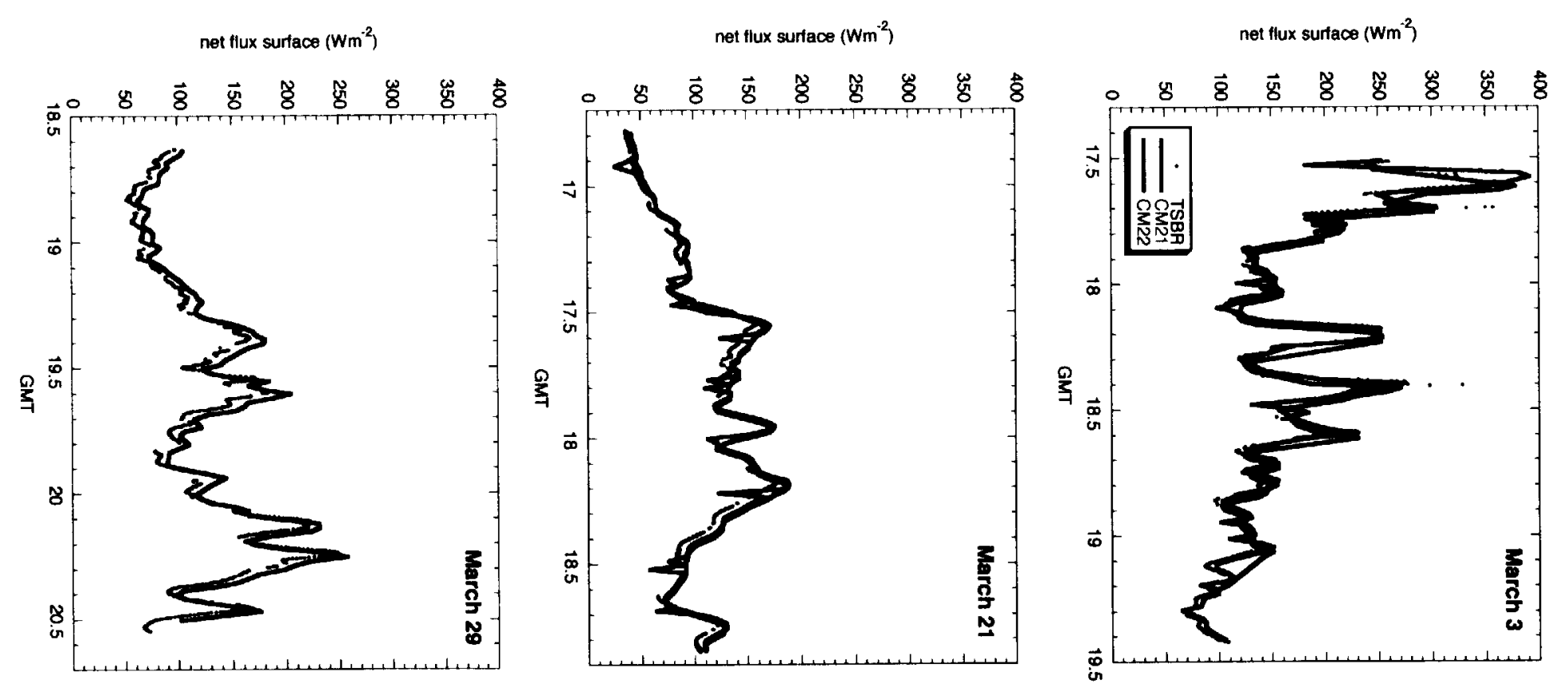


1 


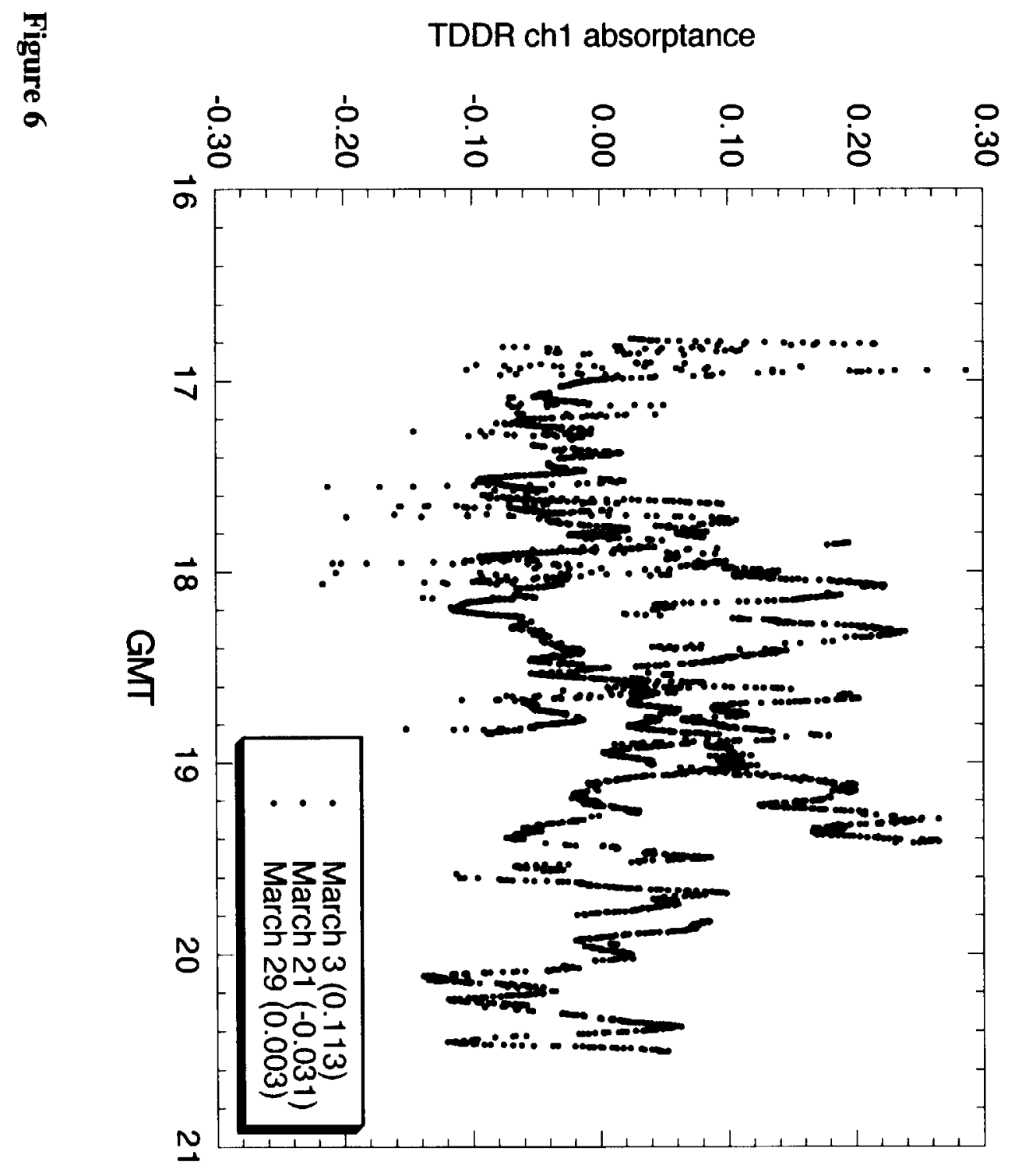


1 

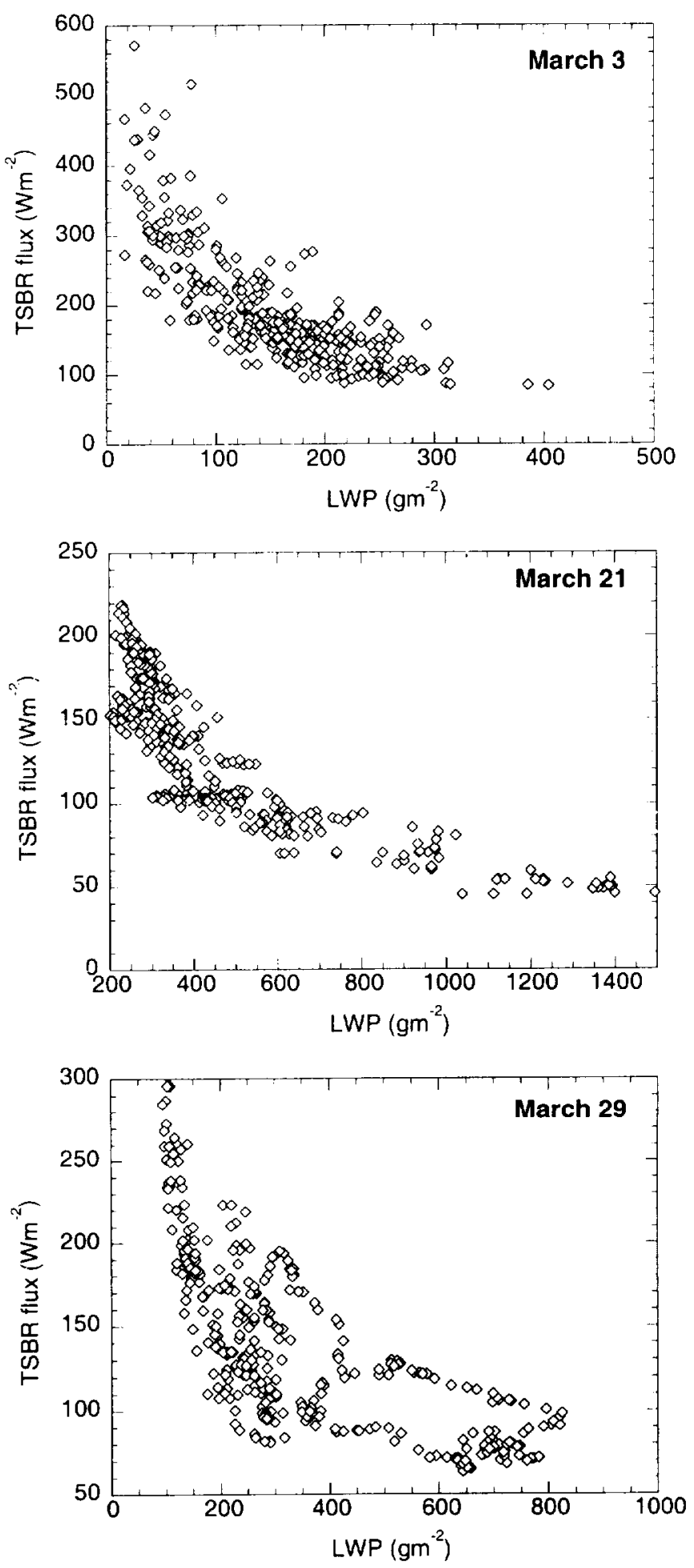

Figure 7 
1 

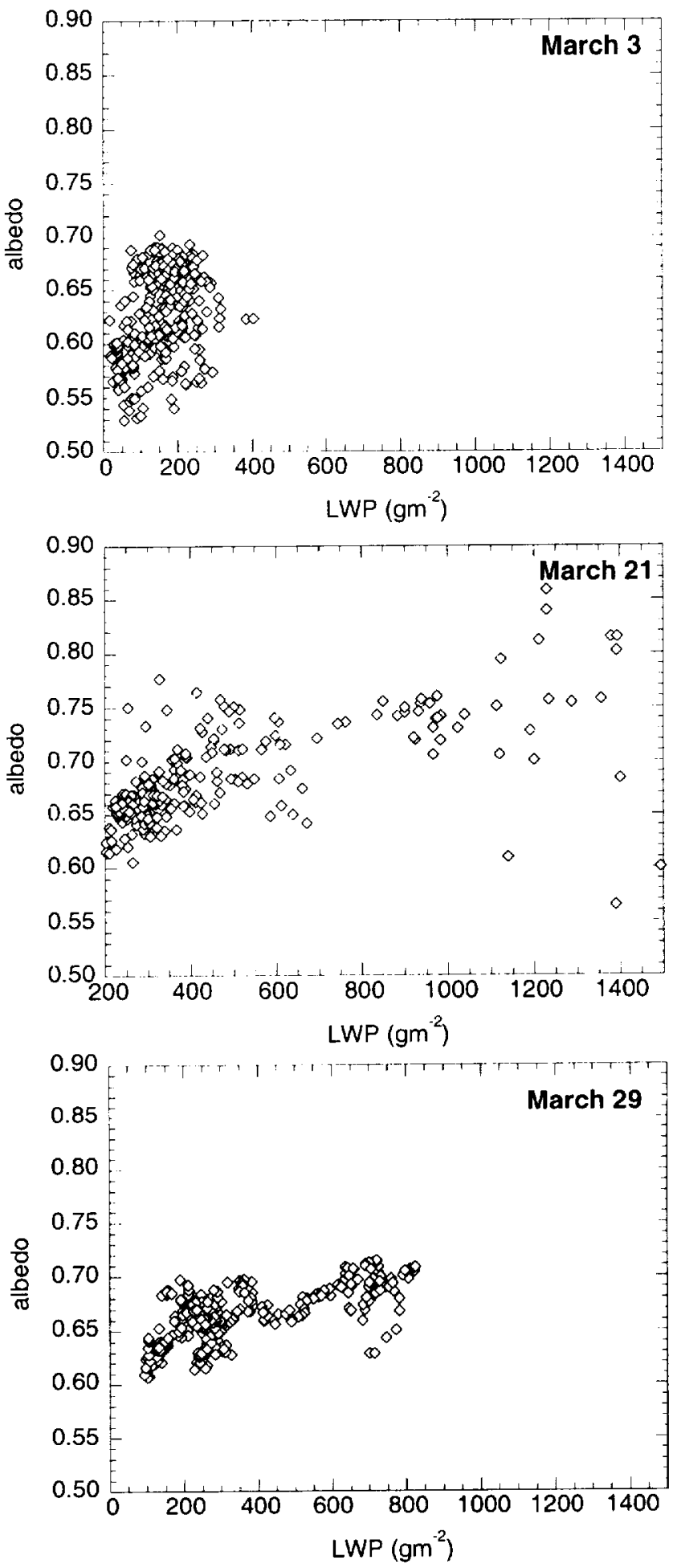

\section{Figure 8}


1 

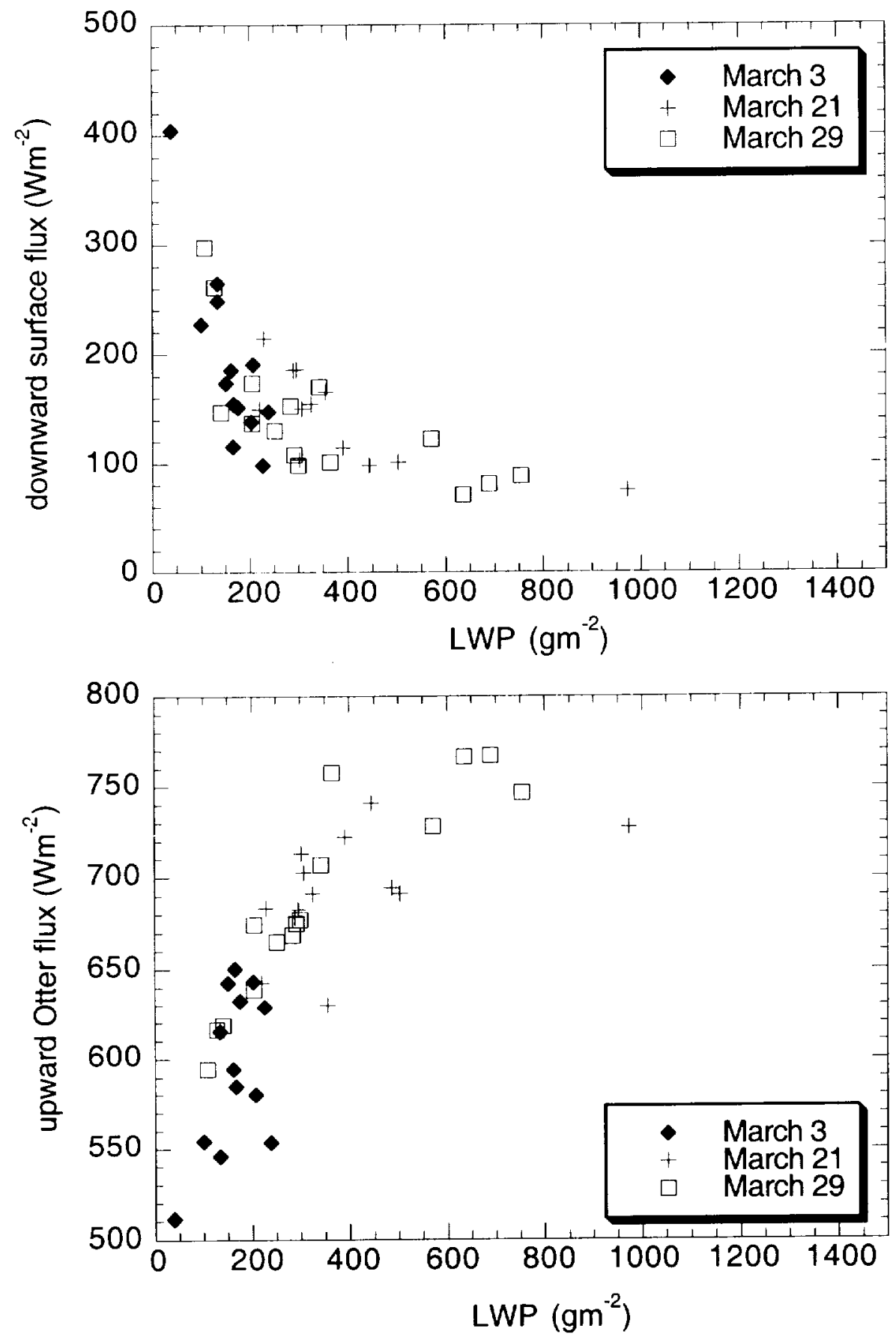

Figure 9 
1 

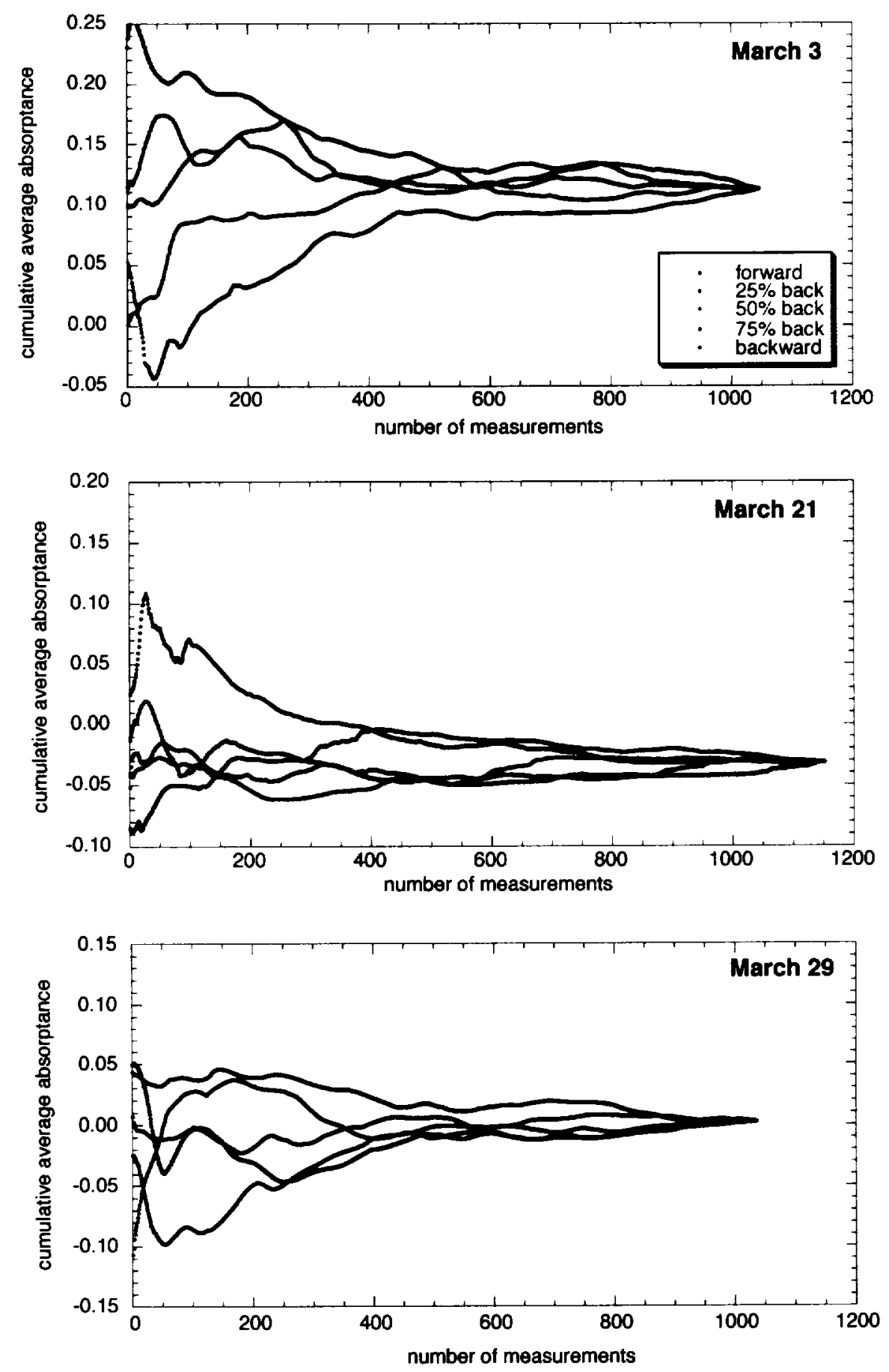

Figure 10 
1 


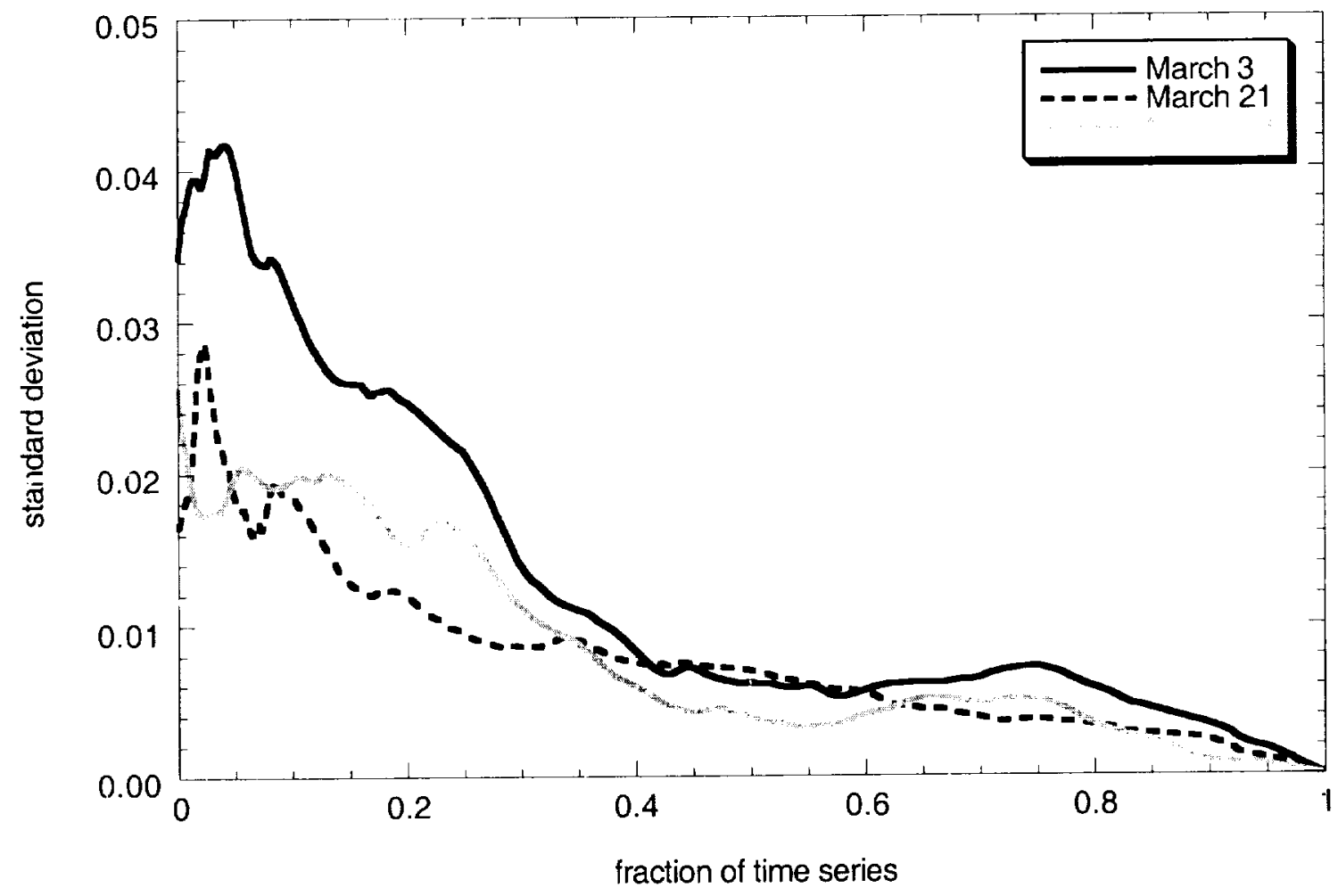

Figure 11 

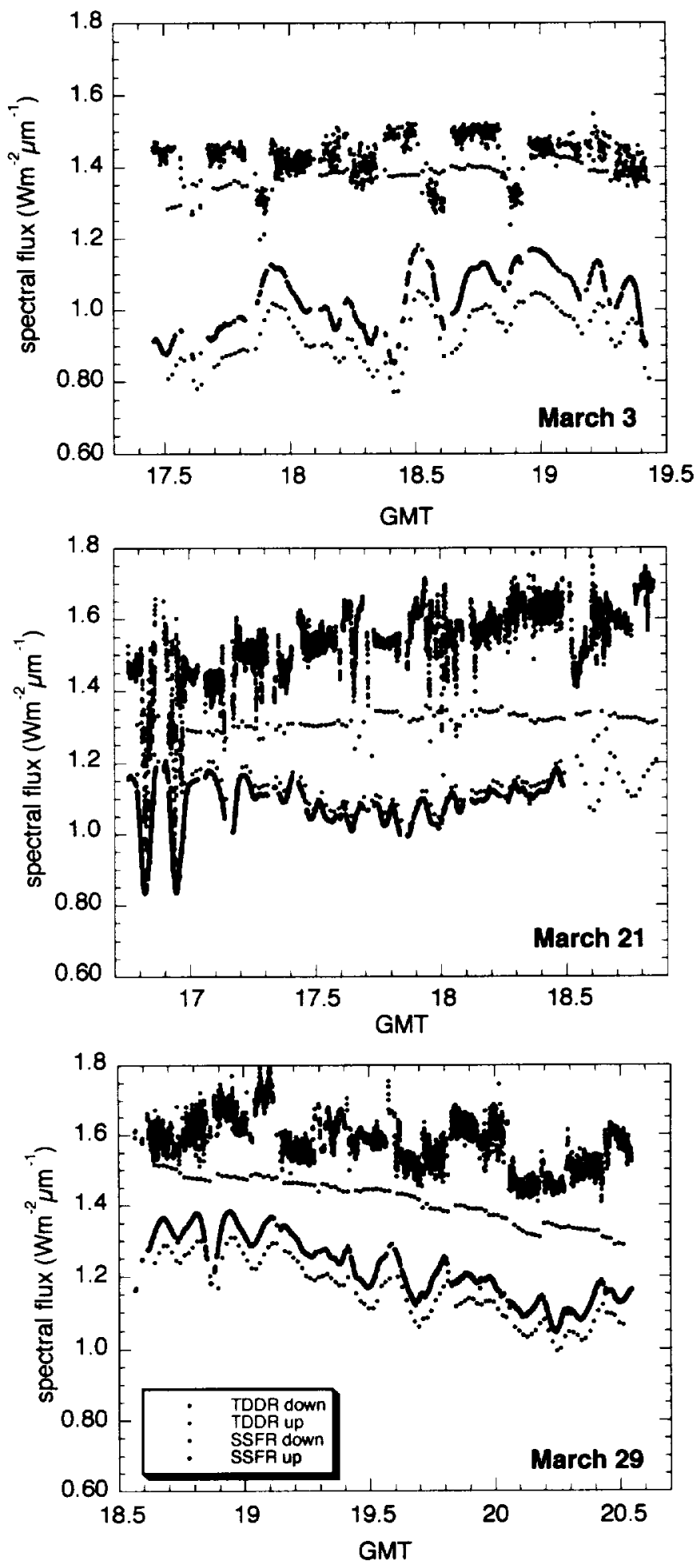

Figure 12 
突
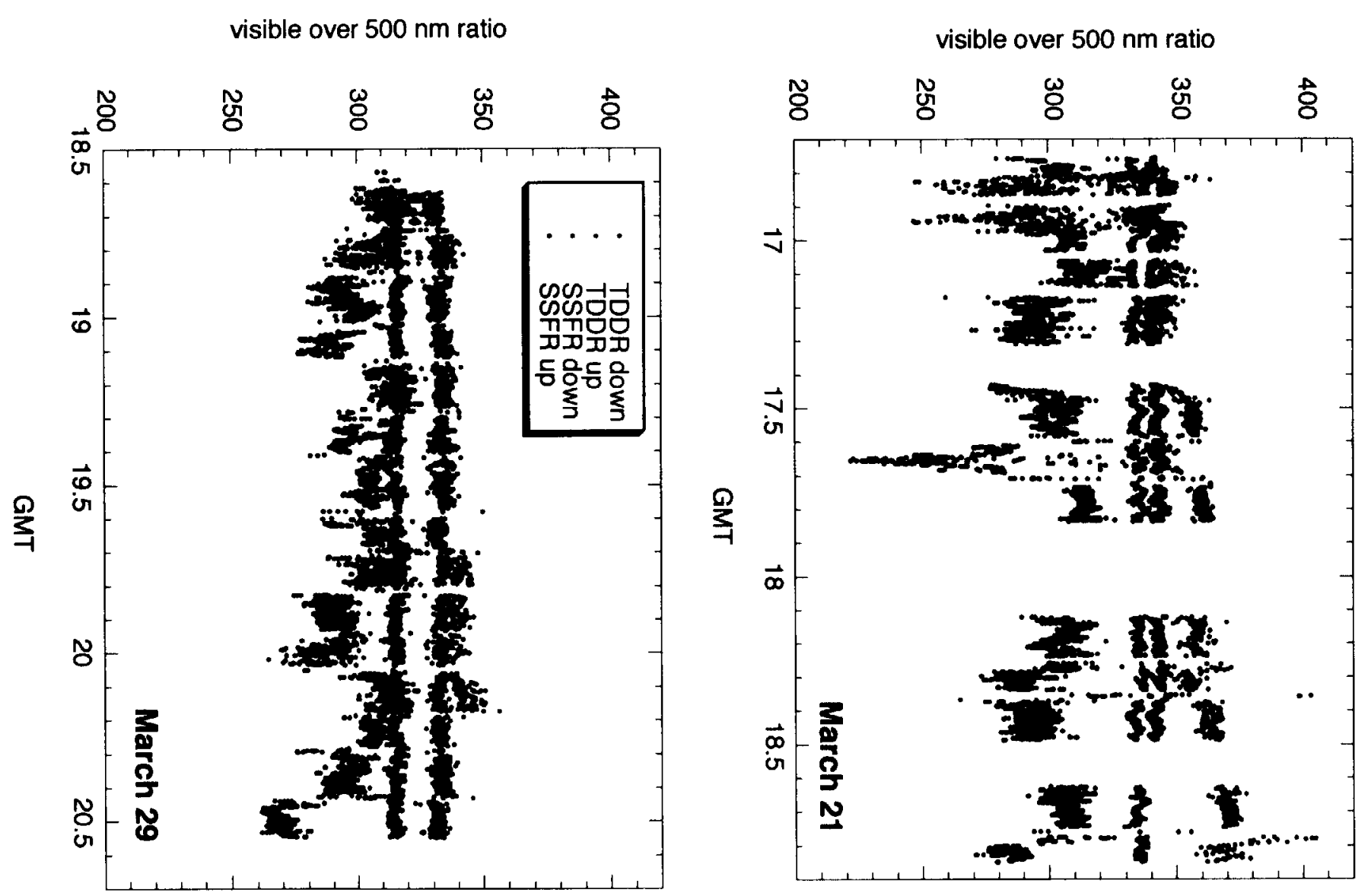
1 

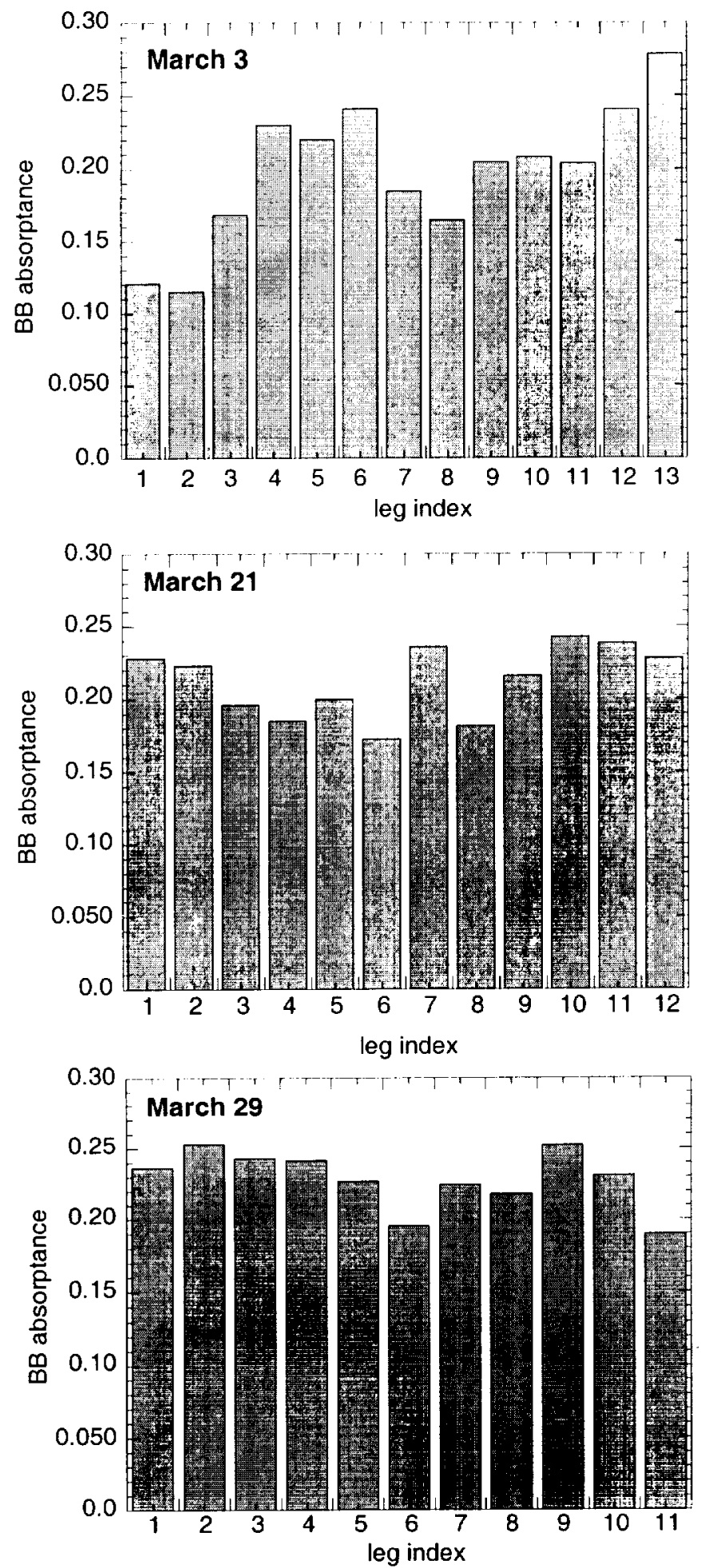

Figure 14 
1 

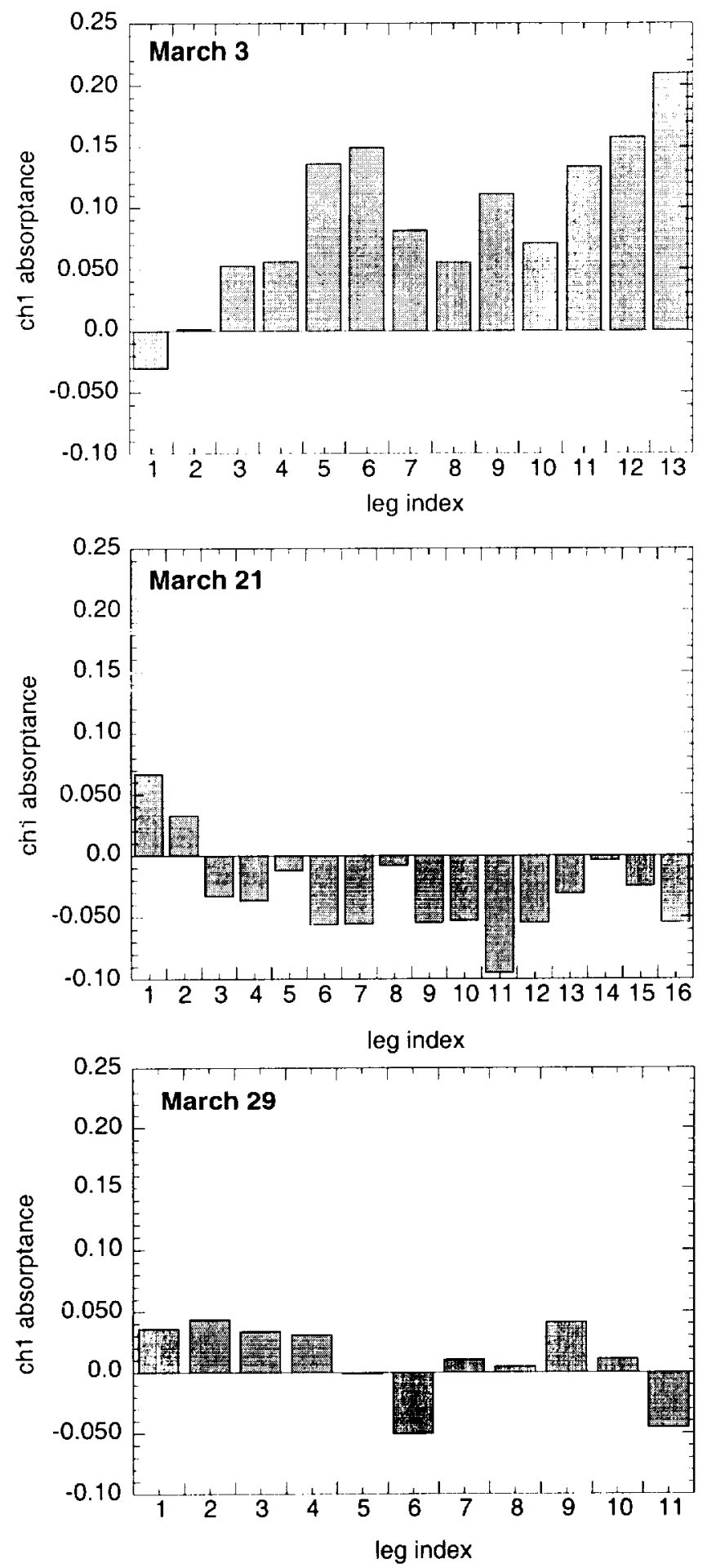

Figure 15 
1 


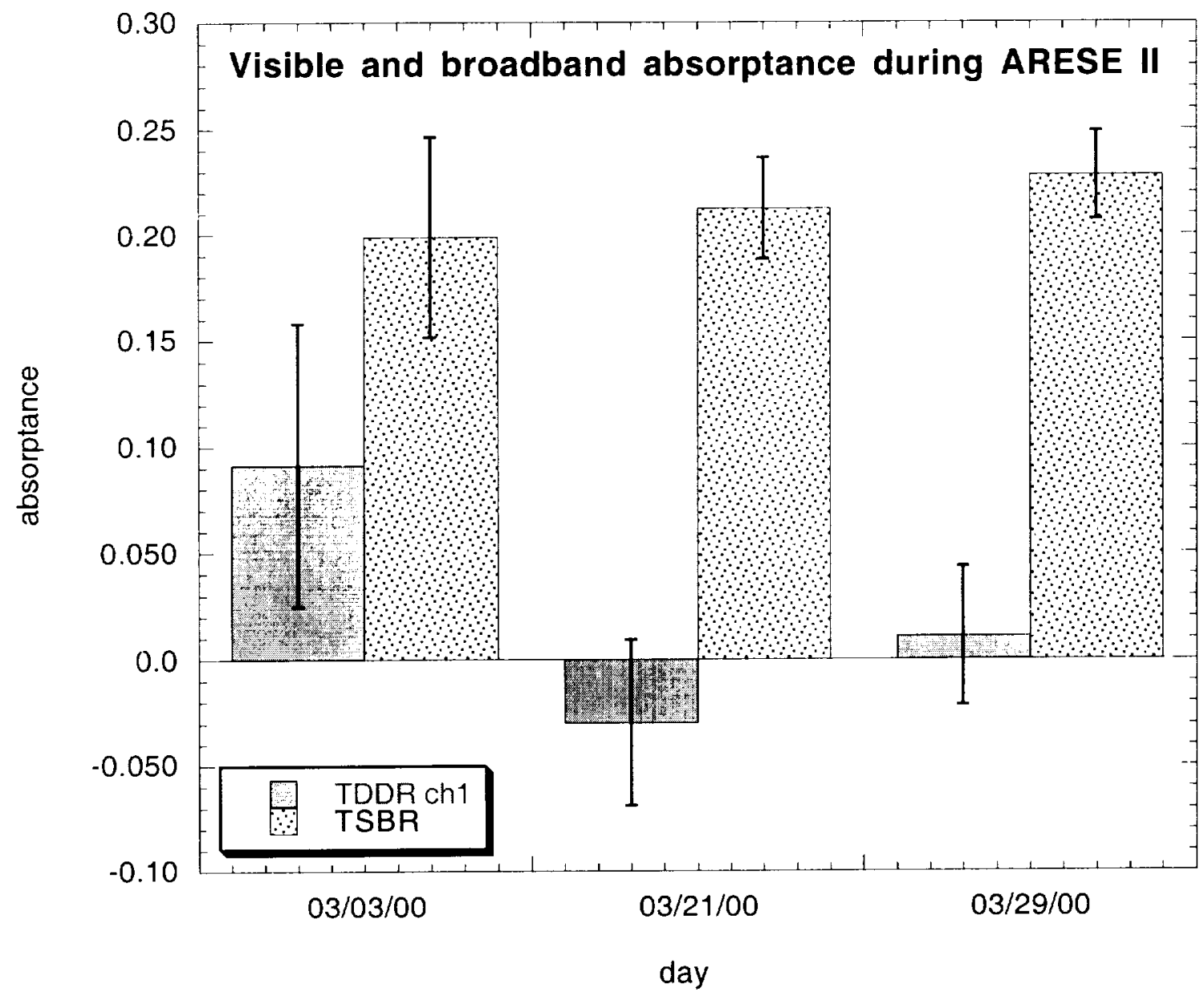

Figure 16 
1 

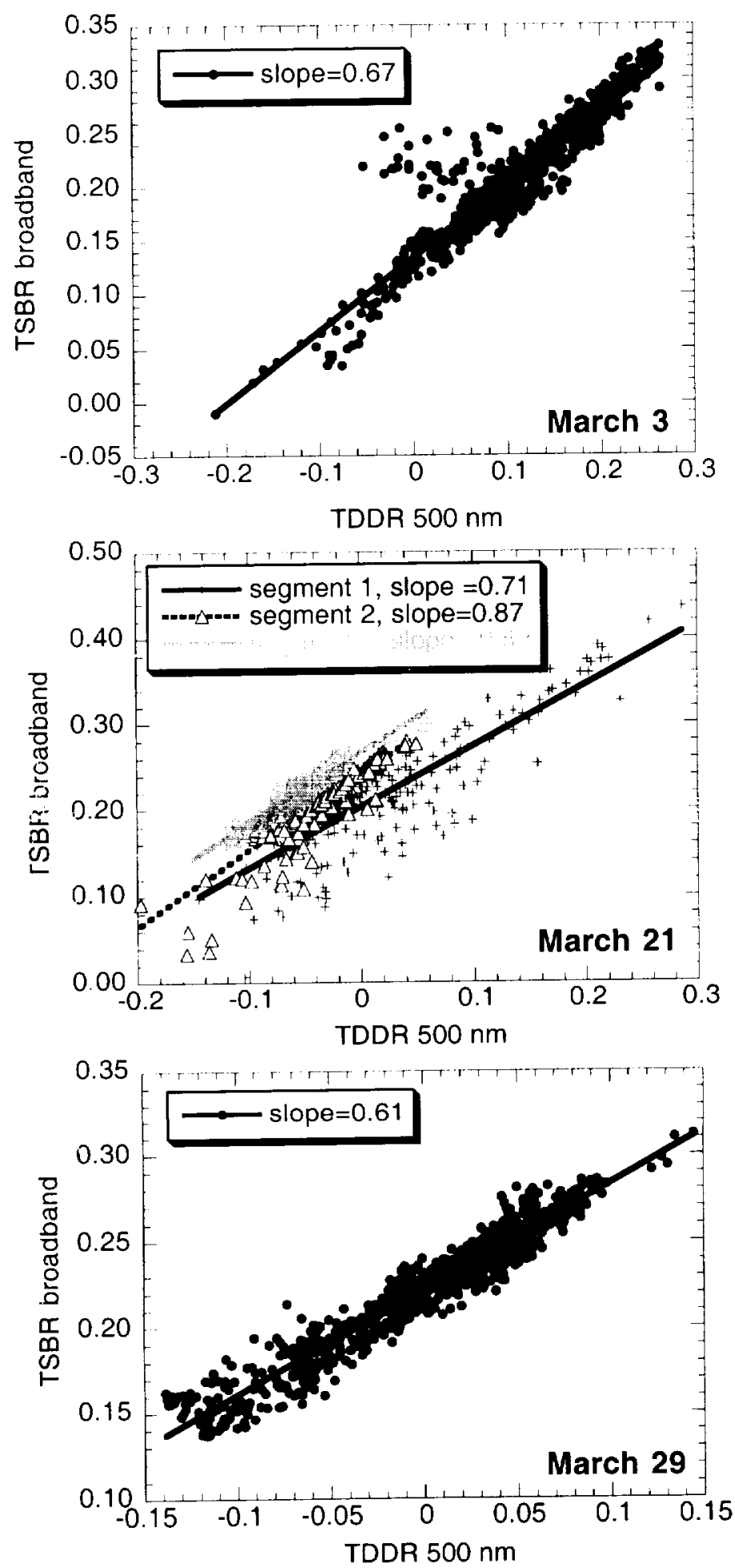

Figure 17 


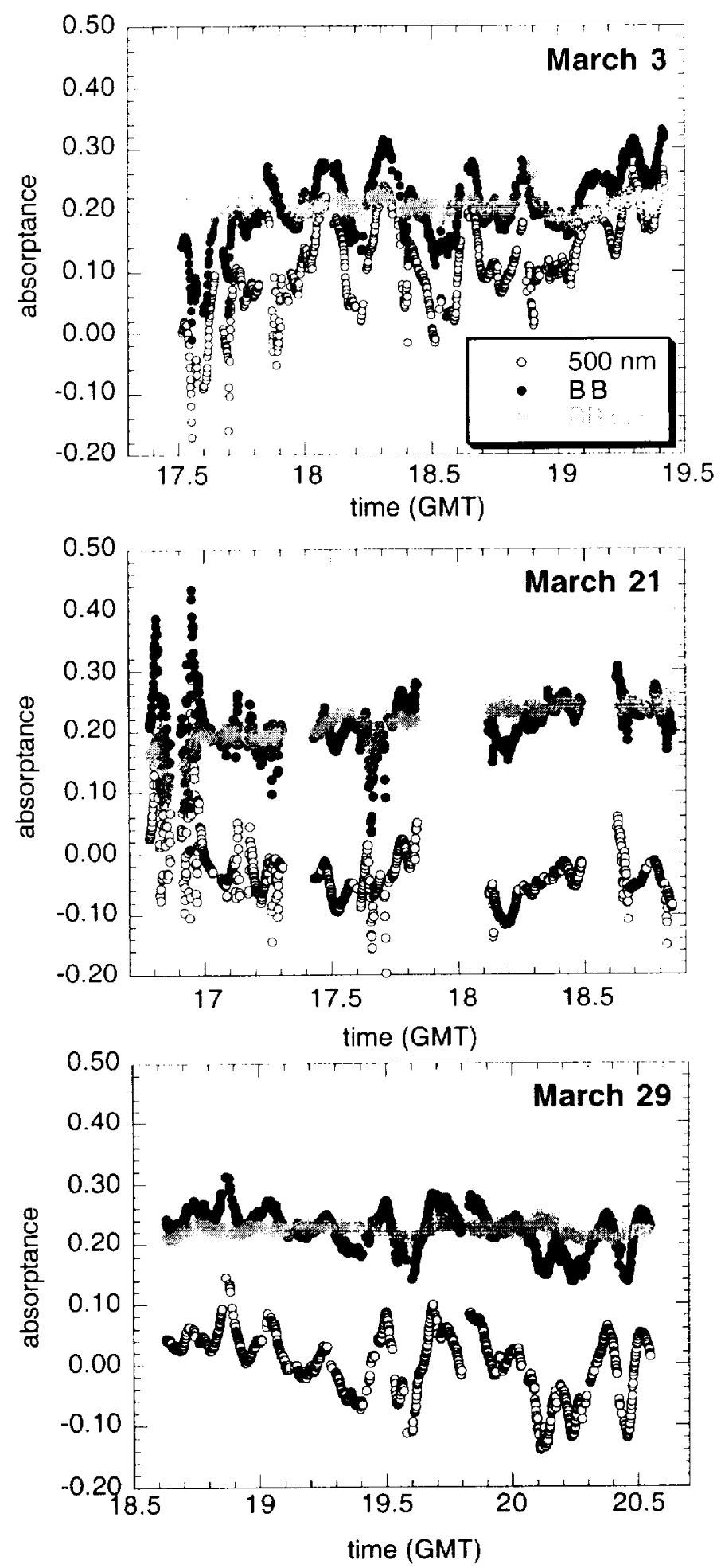

Figure 18 
1 


\title{
Popular summary
}

\section{“ Consistency of ARESE II cloud absorption estimates and sampling issues"}

\author{
L. OREOPOULOS ${ }^{l}$, A. MARSHAK, ${ }^{l}$ aND R. F. CAHALAN ${ }^{3}$ \\ Submitted to: Journal of Geophysical Research (Atmospheres)
}

In order to understand the impact of clouds on climate it is important to know how much solar radiation on average they reflect, transmit, and absorb. Actually, if we know any two of cloud reflection, transmission and absorption, we can infer the third. From these three quantities, it is easier to measure reflection because we measure radiation redirected backwards, and we can get global coverage with satellites, above the clouds. Global estimates of cloud transmission are more difficult to achieve because we need to install instruments that measure solar radiation at the surface. Covering the Earth's surface with such instruments is impractical. Cloud absorption can be calculated if we measure simultaneously at a given location both cloud reflection and transmission. Its estimate is therefore subject to the same limitations as those of transmission; moreover, since it is derived from an equation that involves the reflection and transmission difference, it is more sensitive to error than the other two. Given the difficulty in measuring absorption, it has historically been problematic to match observed and theoretically derived values of cloud absorption for solar radiation. Some investigators, based on evidence from experimental data, have claimed that clouds absorb more than what theory predicts, that is, much more than a cloudless atmosphere.

Our paper analyzes some recent experimental results (Oklahoma, Spring 2000) to provide estimates of cloud absorption, and uses several techniques to determine whether the experiment's design and the type of clouds observed were appropriate for these estimates to be robust. We found that two of the three days analyzed were characterized by clouds that did not meet the criteria set by those who planned the experiment, and erroneous values of cloud absorption could therefore be inferred. For the third day when cloud conditions were more appropriate, cloud absorptances were close to $22 \%$, a value that is much closer to theoretical predictions than previous experimental estimates.

\footnotetext{
${ }^{1} \mathrm{UMBC} /$ Joint Center for Earth Systems Technology

${ }^{2}$ NASA/Goddard Space Flight Center
} 
